\title{
Toxicological Assessment of Nanomaterials: The Role of In Vitro Raman Microspectroscopic Analysis
}

\author{
Esen Efeoglu \\ Technological University Dublin \\ Marcus Maher \\ Technological University Dublin \\ Alan Casey \\ Technological University Dublin, alan.casey@tudublin.ie
}

See next page for additional authors

Follow this and additional works at: https://arrow.tudublin.ie/biomart

Part of the Biochemistry Commons, Nanomedicine Commons, and the Other Analytical, Diagnostic and Therapeutic Techniques and Equipment Commons

\section{Recommended Citation}

Efeoglu, E., et al. (2018).Toxicological Assessment of Nanomaterials: The Role of In Vitro Spectroscopic Analysis. Analytical and Bioanalytical Chemistry, vol. 410, no. 6, pg. 1631-1646. DOI:10.1007/ s00216-017-0812-x

This Article is brought to you for free and open access by the Biomedical and Environmental Sensing at ARROW@TU Dublin. It has been accepted for inclusion in Articles by an authorized administrator of ARROW@TU

Dublin. For more information, please contact

arrow.admin@tudublin.ie, aisling.coyne@tudublin.ie, gerard.connolly@tudublin.ie.

Funder: SFI

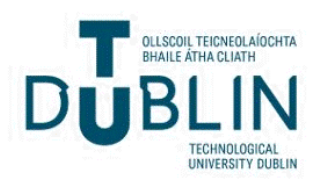




\section{Authors}

Esen Efeoglu, Marcus Maher, Alan Casey, and Hugh Byrne

This article is available at ARROW@TU Dublin: https://arrow.tudublin.ie/biomart/10 
Toxicological Assessment of Nanomaterials: The role of in vitro Raman Microspectroscopic Analysis

Esen Efeoglu ${ }^{1,2, *}$, Marcus A. Maher ${ }^{2}$, Alan Casey ${ }^{1,2}$, Hugh J. Byrne ${ }^{2}$

${ }^{1}$ School of Physics, Dublin Institute of Technology, Kevin Street, Dublin 2, Ireland

${ }^{2}$ FOCAS Research Institute, Dublin Institute of Technology, Kevin Street, Dublin 2, Ireland

*Corresponding Author:

Address: FOCAS Research Institute, Dublin Institute of Technology, Kevin Street, Dublin 2, Ireland

E-mail: esen.efeoglu@mydit.ie

Phone: +35314027902

\begin{tabular}{|l|l|}
\hline Author name & ORCID \\
\hline Esen Efeoglu & $0000-0002-3380-0499$ \\
\hline Marcus A. Maher & $0000-0003-4926-4624$ \\
\hline Alan Casey & $0000-0001-9082-0579$ \\
\hline Hugh J. Byrne & $0000-0002-1735-8610$ \\
\hline
\end{tabular}




\section{Abstract}

The acceleration of nanomaterials research has brought about increased demands for rapid analysis of their bioactivity, in a multi-parametric fashion, to minimise the gap between potential applications and knowledge of their toxicological properties. The potential of Raman microspectroscopy for the analysis of biological systems with the aid of multivariate analysis techniques has been demonstrated. In this study, an overview of recent efforts towards establishing a 'label-free high content nanotoxicological assessment technique' using Raman microspectroscopy is presented. The current state of the art for cellular toxicity assessment and the potential of Raman microspectroscopy are discussed, and the spectral markers of the cellular toxic responses upon exposure to nanoparticles, changes on the identified spectral markers upon exposure to different nanoparticles, cell death mechanisms and the effects of nanoparticles on different cell lines are summarised. Moreover, 3D toxicity plots of spectral markers, as a function of time and dose, are introduced as new methodology for toxicological analysis based on the intrinsic properties of the biomolecular changes, such as cytoplasmic RNA aberrations, protein and lipid damage associated with the toxic response. The 3D evolution of the spectral markers are correlated with the results obtained by commonly-used cytotoxicity assays and significant similarities are observed between band intensity and percentage viability obtained by the Alamar Blue assay, as an example. Therefore, the developed 3D plots can be used to identify toxicological properties of a nanomaterial and can potentially be used to predict toxicity which can provide rapid advances in nanomedicine.

Keywords: Nanotoxicology, cytotoxicity, genotoxicity, Raman microspectroscopy, high content analysis, spectral markers

\section{Introduction: Nanotoxicology}


The increasing interest in, and accelerated research on, naturally occurring or engineered nanomaterials, due to their possible impacts on society in terms of science and technological advancements, has raised questions regarding their health and environmental impact and led to the development of 'Nanotoxicology' as a new branch of toxicology to guide the safe deployment and suitable production of these novel materials [1-3].

Materials of nanoscale dimensions have been identified as possessing extraordinary and sometimes unique physicochemical and optical properties [4-6], which make them invaluable for a wide range of fields such as materials science [7], aerospace [8], cosmetics [9], medicine [10] and the pharmaceutical industry [11], to improve structures and to contribute to the development of new treatment strategies and early diagnosis of many diseases [12-16]. On the other hand, these properties have also been observed to facilitate their interaction with biological systems, which necessitates their responsible use and rapid toxicological analysis to predict possible adverse consequences $[1,17]$. Health organisations have already established plans to promote on-going research in nanoscience as well as nanotoxicology $[18,19]$. The Organisation for Economic Co-operation and Development (OECD) has published a list of nanomaterials with high-economic interest which require immediate investigation in terms of Health and Environmental impact $[19,20]$. The European Union (EU) has established the 'NanoSafety Cluster', which is a consortium of sponsored projects related to toxicology, exposure assessment, mechanism of interaction and risk assessment of nanomaterials in order to maximising the synergy between European level projects [21].

\section{Current Approaches for Toxicological Assessment of Nanomaterial Toxicity}

Most of the strategies that have been proposed for the investigation of nanomaterials include the combinational use of toxicity assays, bio-imaging techniques, chemical and biochemical assays, to obtain information regarding to metabolic activity, membrane integrities, cellular 
viability and cell death mechanisms upon exposure. Cytotoxicity assays have been widely employed to determine cellular viability and also cell death rate in vitro. For example, the tetrazolium salts, such as MTT (3-(4,5-dimethylthiazol-2-yl)-2,5-diphenyltetrazolium bromide), MTS (3-(4,5-dimethylthiazol-2-yl)-5-(3-carboxymethoxyphenyl)-2-(4sulfophenyl)-2H-tetrazolium), $\quad$ XTT (,3-bis-(2-methoxy-4-nitro-5-sulfophenyl)-2Htetrazolium-5-carboxanilide) and WST-1 (2-(2-methoxy-4-nitrophenyl)-3-(4-nitrophenyl)-5(2,4-disulfophenyl)-2H-tetrazolium) (soluble versions of MTT) assays, have been used to determine cellular viability based on the energy-state of the cell $[22,23]$. The Alamar Blue assay $(\mathrm{AB})$, which provides information regarding to overall cell health and proliferative capacity, has also been widely used for determination of nanoparticle toxicity [23-25]. The lactate Dehydrogenase (LDH) [26] and trypan blue [27] assays have been employed to determine cell membrane integrity and cell death rates. For long term toxicity, the clonogenic assay has been employed to determine colony forming efficiency and decreased or increased survival $[28,29]$. Assays such as mitochondrial membrane potential, cellular protonation and reactive oxygen species production have been used to elucidate mechanisms of action of nanomaterials in cells. Assays which measure the activation of caspases, release of inflammatory factors and activation of pro-apoptotic bcl-2 proteins provide further information regarding acute toxic effects of nanomaterials inside the cells. Electron microscopy (EM) and optical microscopy have been used for the visualisation of nanomaterials in cells. Confocal Microscopy (CLSM) has also been used for the visualisation of nanomaterials in cells with the aid of fluorescent labels [30-33]. High Content Analysis/Screening (HCA/HCS), has opened up new perspectivesfor toxicological assesment by providing multifaceted information with high sensitivity based on automated imaging of 'phenotypic assay endpoints'. The technique has been used for in vitro toxicity assesment, animal disease models, drug discovery, 
neurobiology [34, 35], cell signalling [36-38] and observation of biochemical changes [37, 39, 40].

Chronic and genotoxic effects of the nanomaterials have also been widely studied [41-50]. The Ames assay has been employed to observe Gene mutations in Chinese hamster lung (CHL/IU) cells upon exposure to fullerenes [51]. The combination of Ames test, micronuclei assay and comet assay have been used to demonstrate the effect of silver nanoparticles on Chinese hamster ovary cells [52]. HPLC and immunohistological techniques were employed to observe DNA base modifications on the basis of measurement of oxidized guanine upon silica nanoparticle exposure of the human adenocarcinoma cell line (A549) [53]. The comet assay has been used to identify single DNA strand breaks [48]. Northern blot analysis and PCR is widely employed to observe changes in the gene expression $[54,55]$.

Although conventional techniques have provided invaluable information regarding the interaction of nanomaterials with living systems, they remain limited in various aspects, such as the requirement of multiple labels and assays, interference of nanomaterials with the assay dyes [29, 56, 57], cost and also time required for the investigation.

Cytotoxicity assays are based on measurement of a biomarker, or so-called 'endpoint', which usually has a fluorescent property and corresponds to a specific change to the state of the whole cell population [58]. Specificity of the 'endpoints' to a single type of toxicological event, within the cascade of events occurring upon toxicant exposure, results in inconsistencies of results obtained from different assays. Moreover, the nanomaterials can interfere with some of these assays. Carbon Nanotubes have been shown to interfere with the MTT and LDH assays, resulting in misleading results $[29,56,57]$. For the visualisation of the cells, optical microscopy remains limited due to its limited spatial resolution. Even though EM provides very detailed information, some nanomaterials do not provide the contrast and are therefore invisible within 
the cellular environment $[28,59]$. CLSM has invaluable advantages for visualisation of the nanomaterials within the cell, although the low resolution of fluorescent based techniques limits its potential. Also, some nanomaterials cannot be functionalised with dyes and the dye can leak to the environment which reduces the reliability of the results [60, 61]. HCS suffers from the disadvantages of the use of fluorescent dyes and specific'endpoints'. The cost, problems in data management, lack of common standards are also limits in the use of HCS [39].

\section{Raman Microspectroscopy; towards High Content Nanotoxicological Assessment}

\subsection{Raman Spectroscopy}

Although the Raman-effect was first demonstrated by Sir C. V. Raman and K. S. Krishnan in 1928 [62], the developments in high powered light sources such as ion lasers widened the applications of Raman spectroscopy in the late 1960's. The developments in Charged Coupled Detector (CCD) arrays, from the 1980's onwards, added benefits to the high laser source intensities, the significant reductions in acquisition time with multichannel signal detection enabling and significant improvements are achieved in signal to noise ratio [63]. In addition, the development of narrow band laser line rejection filters meant that the huge losses in signal from traditional triple monochomator systems could be overcome with the combination of a filter set and a single spectroscopic grating. Raman spectroscopy, as a vibrational spectroscopic technique, has now become a really powerful technique for the characterisation and identification of biomolecules and biomolecular species, due to the narrow spectral bandwidths and ease of sample preparation [64].

The developing technology of Raman spectroscopy and high potential of the technique in different areas, from medicine to industry, has led to the development of variants of the Raman 
spectroscopy technique itself, such as surface enhanced Raman spectroscopy (SERS) [65], tip enhanced Raman spectroscopy (TERS) [66] and coherent anti Stokes Raman spectroscopy (CARS) [67, 68]. These techniques enable Raman spectroscopy to be more sensitive, to perform molecule specific analysis with enhanced signal.

The applicability of Raman microspectroscopy has been widely shown for the analysis of bodily fluids, tumour tissue margining and analysis of cells and cellular compartments [69-75]. Raman microspectroscopy has been employed to visualise cells as well as their sub-cellular organisation $[73,74,76,77]$. The cellular structures have been identified by combining Raman spectroscopy with immunofluorescence imaging [78], which enabled label-free imaging of live cells. Raman spectroscopy has been also co-registered with fluorescence microscopy for cellular imaging [79]. The differing biochemical composition of nucleus, nucleolus and cytoplasm has also been identified in a completely label free manner, based on intrinsic features of biochemicals $[73,80,81]$. The changes of the spectral signatures upon cell death have been shown by comparing spectral features of dead and live cells [82]. The importance of the use of multivariate analysis techniques such as Spectral Cross Correlation (SCC) and Classical Least Squares (CLS) analysis to extract information from huge Raman data sets has also shown by Keating et al. [76]. Raman spectral phenotyping with the aid of Principal Component Analysis (PCA) has also been studied by comparison of primary cells with cell line models [83].

Furthermore, as a label-free vibrational spectroscopic technique, both Infrared absorption (IR) and Raman spectroscopy have been employed for the localisation of nanomaterials inside the cell [77, 84-86]. Although IR analysis is challenged by the strong contributions of water in biological samples [87], Raman microspectroscopy is not affected to the same degree and has attracted attention for the analysis of biological samples [88]. Raman microspectroscopy also provides higher intrinsic spatial resolution for subcellular imaging compared to IR [89]. 
The correlation between Raman spectral markers of carbon nanotubes (CNTs) and commonly used cytotoxicity assays has been studied by Knief et al. [90]. The studies of Dorney et al. [73] and Keating et al. [76] have shown the localisation of nanoparticles in cells and the use of multivariate analysis techniques to obtain more detailed information regarding to subcellular environment. Confocal Raman microspectroscopy has been employed to study the uptake and localisation of surface engineered CNTs, aluminium oxide and cerium dioxide nanoparticlesat single cell level in HepG2 liver cells [91]. The stress effects of silver nanoparticles as a funtion of applied concentration on human mesenchymal stem cells (hMSCs) has also been studied [92]. Uptake of titania and iron oxide nanoparticles into the nucleus of epithelial cells have been shown using Raman imaging with the aid of multivariate classification [93].

Although there has been huge effort and on-going research in the use of Raman microspectroscopy to explore the cellular interactions of nanomaterials, the studies have been somewhat fragmented and a systematic study of cell-nanoparticle interaction as a function of dose and time has not as yet been reported.

This study aims to aggregate the results of recent studies [46, 50, 74, 94, 95] using Raman microspectroscopic analysis of nanoparticle exposure of cells in vitro, considering cellnanoparticle localisation, spectral marker identification as a function of time and dose, and consistency of the method in different cell lines and for different nanoparticles, with a view towards cohesively assessing its potential as a non-invasive, label-free and High Content Nanotoxicological Screening technique. For specific details of experimental protocols and data processing, the reader is referred to the publications describing the original studies.

In order to establish a toxicological assessment protocol based on Raman microspectroscopy, a progressive and congregate route is followed, from nanoparticle localisation to modelling of 3D plots based on spectral markers of toxicity which will ultimately allow the prediction of toxicity. Different commercially available nanoparticles are used as models throughout the 
study. $40 \mathrm{~nm}$ non-toxic carboxyl-modified polystyrene nanoparticles (PSNPs) are employed to determine nanoparticle localisation and trafficking, whereas $100 \mathrm{~nm}$ toxic amine-modified polystyrene nanoparticles (PS-NH$)$ are used to determine spectral markers of the toxicity. Generation 5 PAMAM dendrimers are used as a secondary toxic nanoparticle model for comparison of spectral markers of toxicity. Moreover, the consistency of the spectral markers in different cell lines has been investigated using model cell lines for cancerous and noncancerous cells. Human adenocarcinoma cells (A549), human lung epidermoid (Calu 1) and human bronchial epithelium cell line (BEAS-2B) are chosen as model cell lines as they mimic one of the primary exposure route of nanomaterials, which is inhalation.

\subsection{Nanoparticle uptake and Trafficking}

Raman microspectroscopy has been employed to determine the localisation of non-toxic carboxylated polystyrene nanoparticles inside the cellular transport organelles, including early endosomes, lysosomes and endoplasmic reticulum, as a function of time following their uptake [74]. Confocal microscopy with different organelle staining was used to determine the localisation of nanoparticles from 4 to $24 \mathrm{~h}$. Raman microspectroscopy was used to map the sub-cellular regions, at determined time points by confocal microscopy, to extract information regarding to nanoparticle localisation as nanoparticles are trafficked inside the cell.

Due to the variability of surface properties and size of the nanomaterials, cell-nanomaterial interaction can occur in various ways. However, one of the primary uptake mechanisms of the nanoparticles is known to be endocytosis [96]. Although different mechanisms of endocytosis have been identified [97], endocytosis can be described as uptake of nanomaterials in membrane based vesicles. The confocal study showed the uptake mechanism of the carboxylated PSNPs by endocytosis and PSNPs are observed in early endosomes within $4 \mathrm{~h}$. Then, PSNPs are carried to lysosomes which act as the digestion/recycling system of the cells 
(12 h). After $12 \mathrm{~h}$ exposure of cells to the PSNPs, they are further trafficked to the endoplasmic reticulum, considered the final localisation point [74]. The Raman spectroscopic mapping of subcellular regions after 4, 12 and $24 \mathrm{~h}$ exposure to the PSNPs provided invaluable information regarding not only nanoparticle localisation but also identification of Raman signatures of organelles with the aid of multivariate analysis techniques. Early endosomes, lysosomes and endoplasmic reticulum are mainly composed of lipids which make them difficult to differentiate from each other. However, the study showed the potential of Raman microspectroscopy to differentiate organelle signatures based completely on their intrinsic biochemical properties in completely label-free manner. The differentiating spectral signatures are best viewed as the PCA loadings of 4, 12 and 24 h nanoparticle exposure data sets obtained from pairwise comparison of particle cluster and environment. Fig.1 shows varying the spectral signatures of endoplasmic reticulum, lysosome and endosomes after 4, 12 and 24 h carboxyPSNP exposure. The main differences on the spectral profiles of different organelles are highlighted with grey and some of the spectral markers are provided in Fig.1.

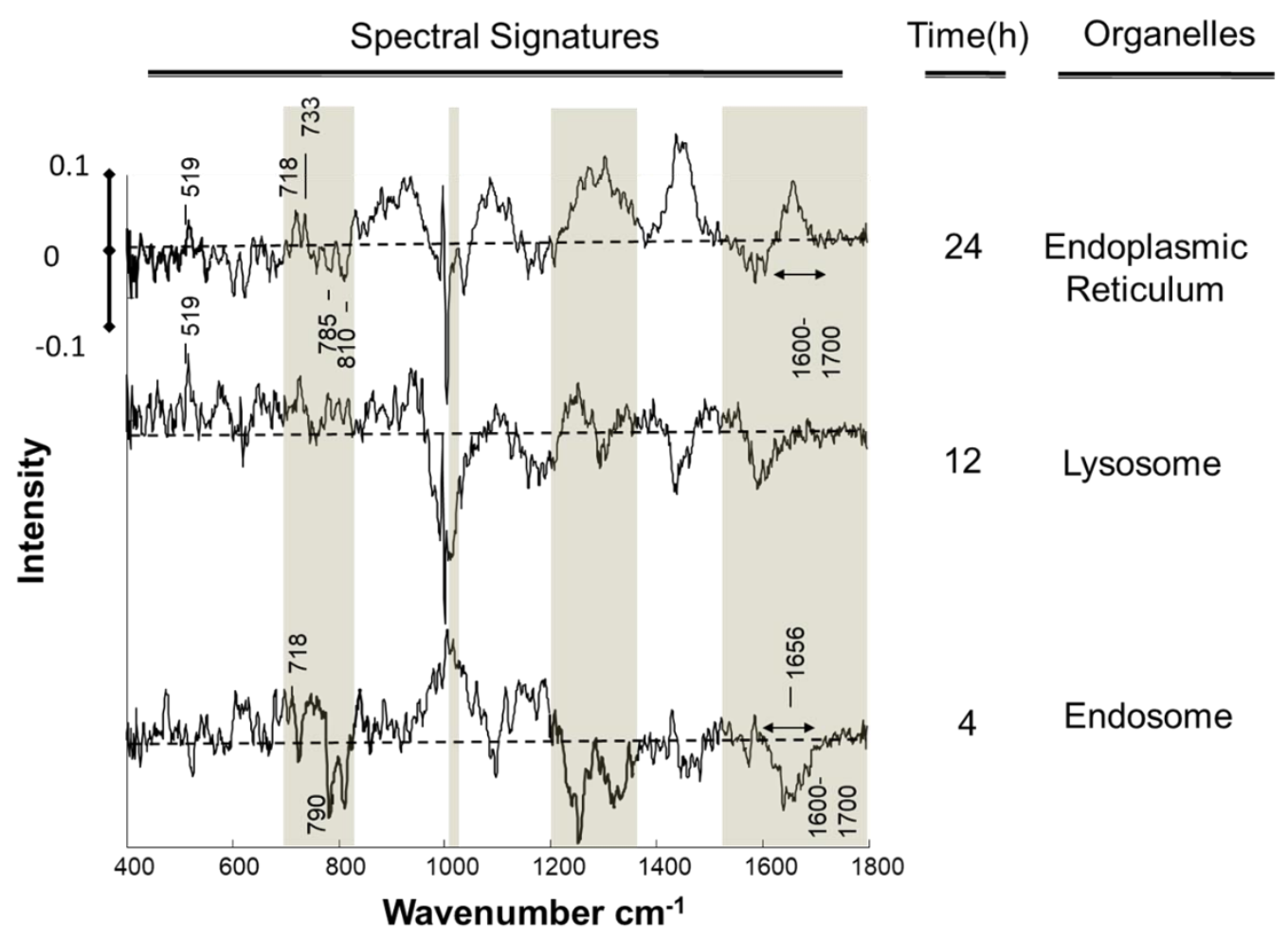


Fig.1 Comparison of PCA loadings of 4, 12 and $24 \mathrm{~h}$ nanoparticle exposure data sets. Loadings are offset for clarity. The dotted line represents the zero ' 0 ' point for each loading and intensity scale of $0 \pm 0.1$ is used for comparison. The figure is adapted from [74].

\subsection{Acute toxicity of Nanoparticles}

\subsubsection{Effects of Nanoparticles in Cytoplasm}

While carboxylated and neutral PS nanoparticles are known to be non-toxic, their aminated counterparts are known to show acute toxicity as a result of oxidative stress in the endosomal and lysosomal pathway [46, 73, 74,]. In order to observe acute toxicity and corresponding responses, time and dose dependant Raman spectroscopic markers of cellular toxic events were systematically monitored upon $\mathrm{PS}-\mathrm{NH}_{2}$ and PAMAM exposure to cancerous and noncancerous cells $[46,50,94,95]$.

Upon PS- $\mathrm{NH}_{2}$ exposure, the most dominant spectral marker is observed to be the 'doublet band' at 785 and $810 \mathrm{~cm}^{-1}$ in the cytoplasm, which indicates a change in the cytoplasmic RNA as a result of ROS formation and the doublet band is observed in particle exposed cells even at low doses $\left(\mathrm{EC}_{25}\right)$ and short exposure times (after $\left.4 \mathrm{~h}\right)$. The intensity of the band systematically and progressively changed as a function of dose and exposure time [46]. The doublet band was also observed in the biochemical features of Calu 1 cells following $\mathrm{PS}_{-} \mathrm{NH}_{2}$ exposure and progressively changed with extended exposure times [50]. When, a second toxic nanoparticle model, PAMAM dendrimers, was introduced to the A549 cells, a similar trend to that for PS$\mathrm{NH}_{2}$ is observed for the double peak at 785 and $810 \mathrm{~cm}^{-1}$, which, together, with the results obtained from different cell lines and nanoparticle models, validates the changes in cytoplasmic RNA to be a spectral marker of toxicity [94]. The changes in the doublet band, upon exposure to PS- $\mathrm{NH}_{2}$, are followed by concomitant and subsequent changes in the higher end of the 
fingerprint which provides information about protein (Amide I region) and lipid damage (1229 and $1438 \mathrm{~cm}^{-1}$ ). The band at $1438 \mathrm{~cm}^{-1}$, which has been identified upon $\mathrm{PS}-\mathrm{NH}_{2}$ exposure, was also identified after exposure to PAMAM dendrimers and it has been observed to provide information regarding to lipotoxicity $[46,50,94]$. Therefore, it can be concluded that Raman spectroscopy identifies signatures of the initiating toxic response and following cellular dependant events, in real-time single assay and notably, brings new aspect to determination of nanomaterial toxicity by identifying cytoplasmic RNA as a spectral marker, which is not normally identified by conventional toxicity assays. Moreover, the doublet band can be seen as the first strong spectroscopic response of oxidative stress. Although, it does not measure the ROS directly, it provides information about the response, which is a ROS related change in cytoplasmic RNA. The onset of ROS formation upon nanoparticle exposure has been observed to be within 2-6 h $[98,99]$, and this initial stage of ROS dies away due to the action of intracellular antioxidants with a similar timescale [98]. In contrast, the doublet band is observed only after $8 \mathrm{~h}$ exposure to $\mathrm{PS}-\mathrm{NH}_{2}$ and increases further with exposure time. Fig. 2 shows the loadings of PCA obtained from pairwise comparison of particle exposed cells $(24 \mathrm{~h})$ and corresponding controls. Positive and negative features of the loadings relate to exposed and unexposed cells, relatively and the figure summarises spectral markers of acute toxic response in the cytoplasm, identified by Raman microspectroscopy. 


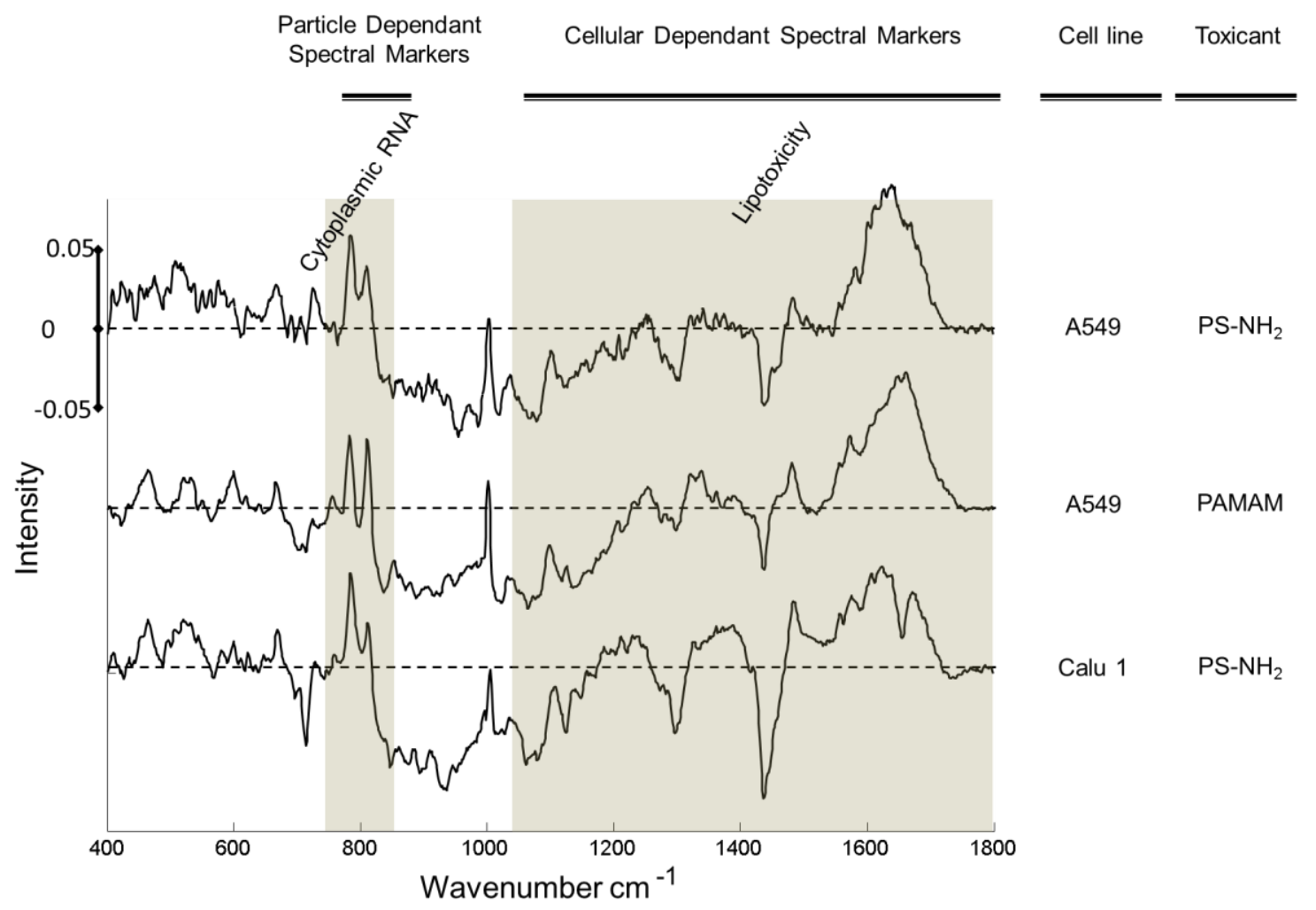

Fig.2 Spectral Markers of acute toxic response in the cytoplasm of A549 and Calu 1 cells after $24 \mathrm{~h}$ exposure to PS-NH 2 and PAMAM nanoparticles. Positive and negative features of the loadings relate to exposed and unexposed cells, relatively. The $750-830 \mathrm{~cm}^{-1}$ and above $1000 \mathrm{~cm}^{-1}$ region are indicated with highlights. Loadings are offset for clarity. The dotted line represents the zero ' 0 ' point for each loading and intensity scale of $0 \pm 0.05$ is used for comparison $[46,50,94]$.

The potential of Raman microspectroscopy as a single label-free technique with multiparametric information was further analysed by focusing on the validation of the technique by comparing spectral marker evolution in non-cancerous cells lines with cancerous cell lines [50] to build a 'high content' and 'label-free' Nanotoxicological assessment protocol. The spectral markers of toxic events such as oxidative stress and lysosomal damage have been identified as a function of time and the study showed that the identified spectral markers for cellular 
dependant events show consistency across multiple cell lines which allow the identification of mechanism of action of the nanomaterial. The findings from the comparison of presence and progression of spectral markers, especially in low wavenumber region, have also shown the applicability of Raman spectroscopy to identify different cell death pathways in cancerous and non-cancerous cell lines (Fig.3) [50], Positive and negative features of the loadings relate to exposed and unexposed cells, relatively. The study showed the potential of Raman spectroscopy to provide further information regarding the mechanism of action as a single label free assay, without use of multiple labels and assays.
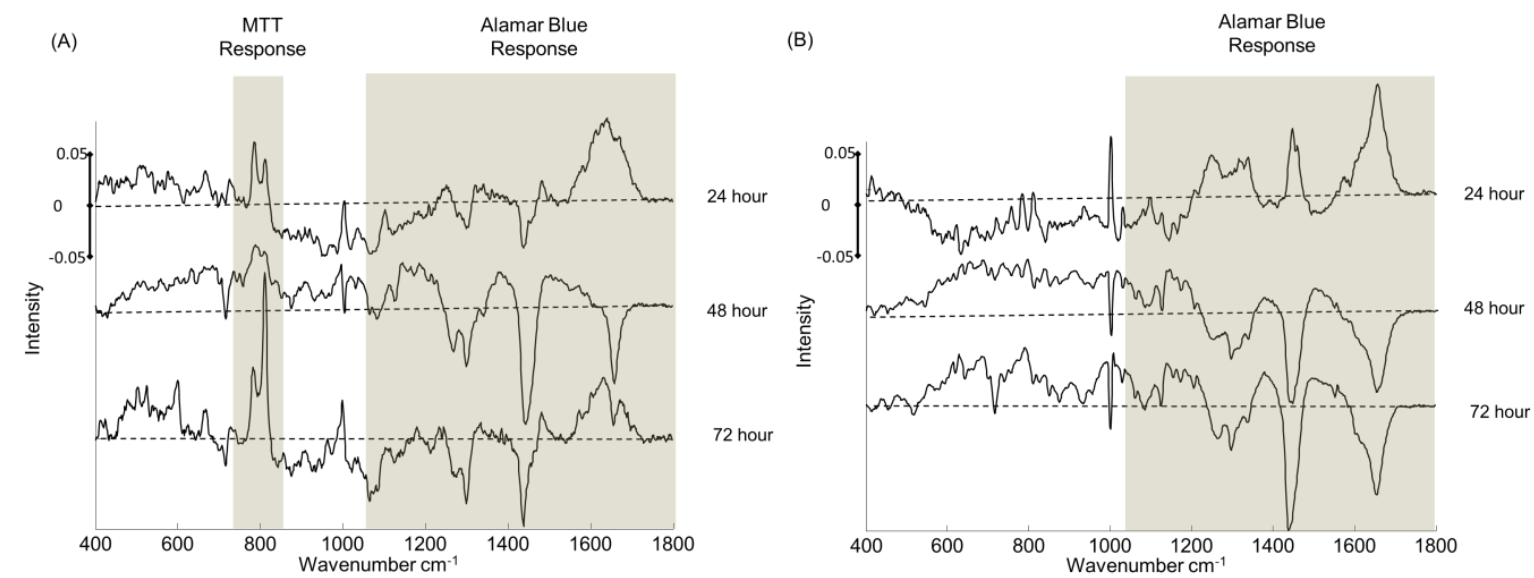

Fig.3 Spectral markers of cell death on cancerous (A) and non-cancerous (B) cell lines and cytotoxicity assays which are found to be related the changes on these spectral markers. Loadings are offset for clarity. The dotted line represents the zero ' 0 ' point for each loading and intensity scale of $0 \pm 0.05$ is used for comparison. The figure is reproduced from the study of Efeoglu et al. [50].

\subsubsection{Effects of Nanoparticles in the Nucleus and Nucleolus}


Another notable outcome from the study has been determined to be the genotoxicity spectral markers. The spectral features of the nucleus and nucleolus showed significant changes as a function of time and dose upon PAMAM exposure. Nanoparticles such as PAMAM dendrimers are not fluorescent and do not provide contrast for EM studies, which makes cellular interaction studies challenging. Moreover, the small size of these dendrimers $(\sim 2-10 \mathrm{~nm}$, depending on dendrimer generation) [100] makes them unsuitable for fluorescent labelling, which significantly changes their size and potentially their toxic properties. However, the use of Raman spectroscopy and systematic changes to the spectral signatures of biochemical composition of the cells can be used to elucidate their interaction with DNA and RNA inside the nucleus. The spectral range from 750 to $830 \mathrm{~cm}^{-1}$ is particularly useful to represent the mechanism of action of small non-fluorescent nanomaterials in nucleus and nucleolus. By comparison of PAMAM/DNA and PAMAM/RNA interactions, possible final localisation in the cells has been identified as the nucleolus which is not possible to observe with other current techniques. Spectral signatures of the post-translational modifications and corresponding biochemical changes, information which normally requires the use of multiple assays, have also been identified.

The high degree of consistency upon exposure to different toxicants indicates a promising future for the use of those spectral markers identified by Raman microspectroscopy in nanotoxicology and nanomedicine. Based on the similar trends for the toxicity of different nanoparticles, the evolution of the spectral markers was further investigated to identify common and/or differing spectral markers of toxicity [95]. The findings of the study showed that, although spectral markers of cytoplasmic RNA, lipid and protein damage show consistencies, their evolutions show differences as a result of different response rates. Therefore, it can be concluded that Raman spectroscopy can give not only multi-parametric information based on intrinsic features of biochemicals upon toxicant exposure but also their 
response rates. Notably, in this study, especially at extended exposure times, a significantly different evolution of spectral markers has been observed for the two different types of toxic nanoparticles, which can be attributed to different cell death mechanisms. Although the changes were more significant at long exposure times, the different response rates of the bands at early time points also provided information regarding the different cell death mechanisms. Cell death upon toxicant exposure can occur in multiple ways, most notably apoptosis and necrosis. The conventional apoptosis/necrosis assays use colorimetric identification based on cellular uptake of dyes and give information related to whether apoptotic or necrotic cell death has occurred. However, Raman microscopy not only provides information regarding whether the cell is apoptotic or necrotic, but also the biochemical path leading to this differentiation (Fig.4).

(A)

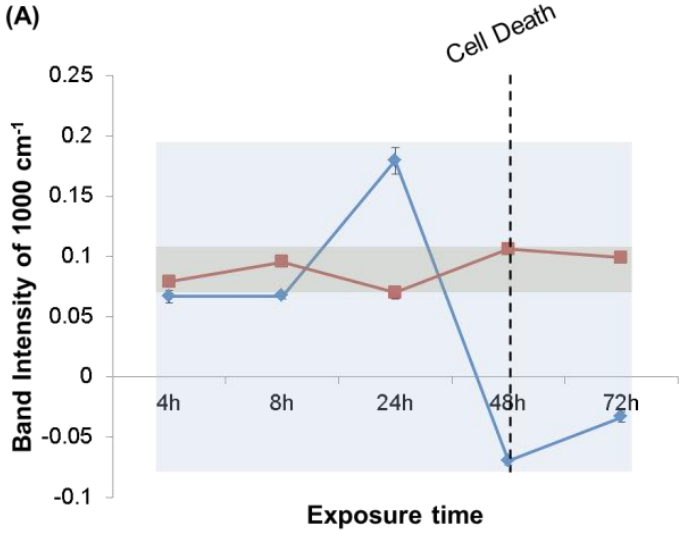

(C)

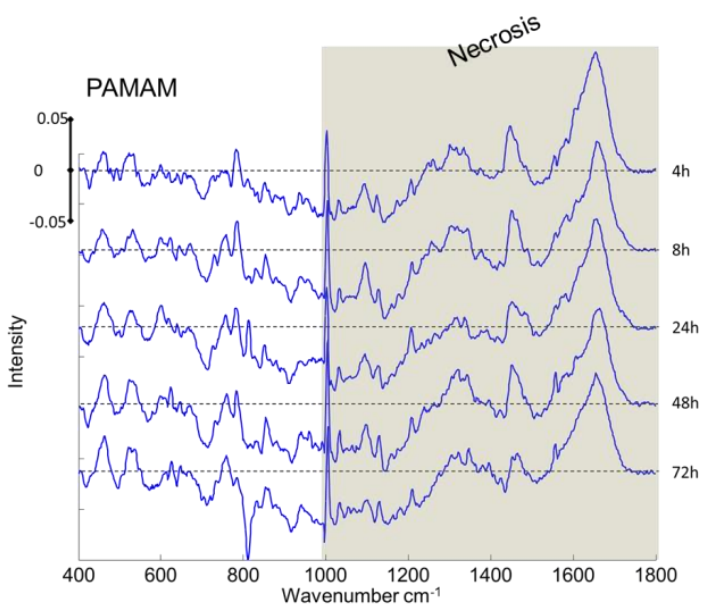

(B)

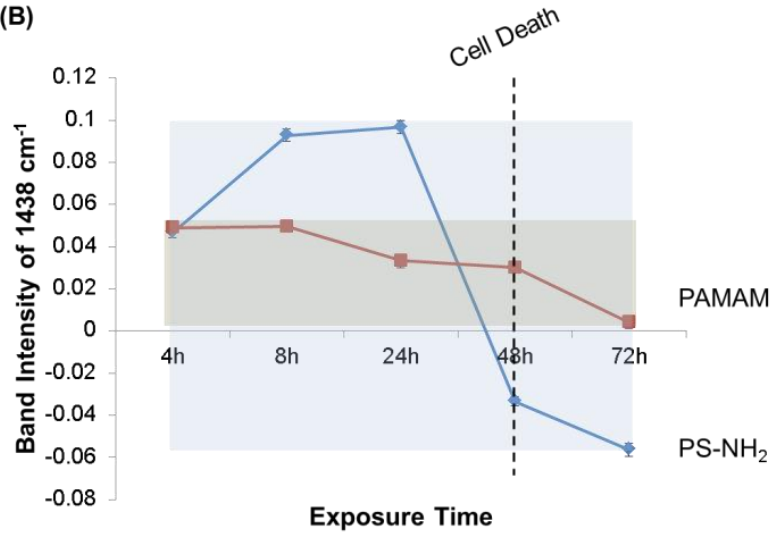

(D)

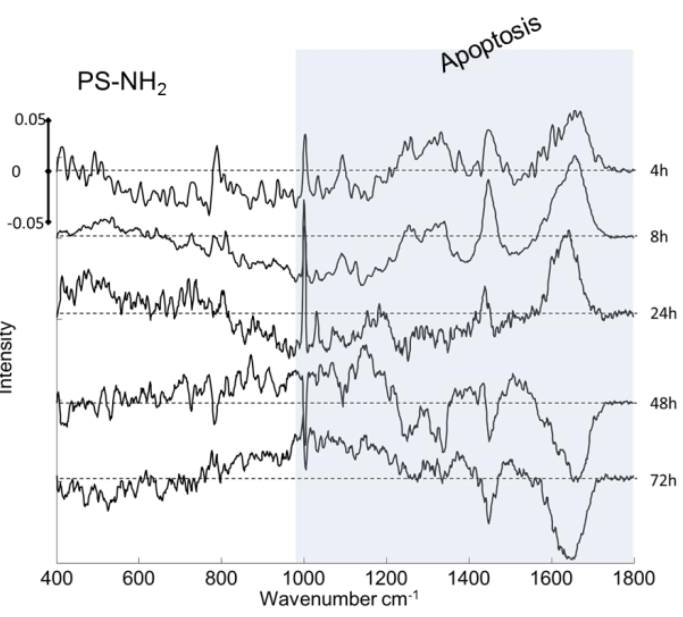


Fig.4 Spectral marker profiles of apoptotic and necrotic cell death. Comparison of Band intensities of 1003 (Phenlyalanine) (A) and 1438 (Lipids) (B) $\mathrm{cm}^{-1}$ bands calculated from PC1 from pairwise PCA of nucleus of exposed cells and corresponding control. Comparison of PC1 obtained from pairwise PCA of nucleus of exposed cells and corresponding control for 4, 8, 24, 48 and $72 \mathrm{~h}$ PAMAM-G5 (C) and PS-NH 2 (D) exposure. The changes in the band intensities for PS-NH 2 and PAMAM-G5 exposure are indicated with blue and red lines, respectively. Data are expressed as $\%$ of control mean \pm SD. The negative side of the loading represents the spectral features of control, whereas positive side represents the cells exposed to PS-NH $\mathrm{NH}_{2}$ and PAMAM-G5. Loadings are offset for clarity. The dotted line represents the zero ' 0 ' point for each loading and intensity scale of $0 \pm 0.05$ is used for comparison [46, 50 , 94, 95].

Adopting the terminology of the Adverse Outcome Pathway methodology [101], upon exposure to a toxicant, the response begins with a molecular initiating event (MIE) which induces a cascade of consequent events. In the current context, the MIE is identified as the initial oxidative stress caused by the ingestion of the nanoparticles in exosomes and ultimately results in a change in cytoplasmic RNA, manifest as changes in the doublet peak of $785 \mathrm{~cm}^{-1}$ and $810 \mathrm{~cm}^{-1}$. The study of Maher et al.[102] showed that the MIE shows particle dependency and induces cellular dependant events which can include, for example, changes in mitochondrial function, activation of caspases, and release of inflammatory factors. However, conventional and commonly used cytotoxicity assays use specific markers which can be defined as 'endpoints' and identify the toxicity as a function of half-maximal effective dose ' $\mathrm{EC}_{50}$ '. Therefore, these assays remain limited to provide information regarding to multiple events that occur concomitantly or consecutively inside the cell. Raman microspectroscopy shows signatures of this cascade as presence of spectral markers of initiating toxic event at low doses and short exposure times in low wavenumber region (cytoplasmic RNA, indirect ROS), 
followed by concomitant changes (Protein and lipid damage as a result of cellular toxic events) in high wavenumber region of fingerprint.

\subsection{D Toxic Response to Nanoparticles Determined by Raman Microspectroscopy}

A notable finding from the studies based on comparison of the spectral profiles was the 3D dimensional correlation of the spectral markers. The 3D response surface of cytotoxicity has previously been highlighted [102], whereby similar responses are elicited when cells are exposed to higher concentrations of a toxicant for short exposure time and low concentrations for longer exposure times. This 3D relationship is also evident in the time and dose dependences of the spectral markers identified by Raman microspectroscopy. Fig.5 shows the loadings of PC1 obtained from pairwise comparison of cytoplasm of particle exposed cells with their corresponding controls. The positive features represent the biochemical composition of the particle exposed cells, whereas negative features represent the composition of control cells. As seen in Fig.5(A), the loadings of the PCA from the cytoplasm of PS- $\mathrm{NH}_{2}$ exposed cells show similar trends when cells are exposed to $10 \mu \mathrm{M}$ (lethal dose) of $\mathrm{PS}-\mathrm{NH}_{2}$ for $8 \mathrm{~h}$ and 2.5 $\mu \mathrm{M}$ (sublethal dose) for $48 \mathrm{~h}$. Moreover, the 3D response effect is observed for PAMAM dendrimers even between sublethal doses and the loadings showed similar features when the cells are exposed to $\mathrm{EC}_{10}$ for $24 \mathrm{~h}$ and $\mathrm{EC}_{25}$ for $8 \mathrm{~h}$ (Fig.5(B)). 
(A)

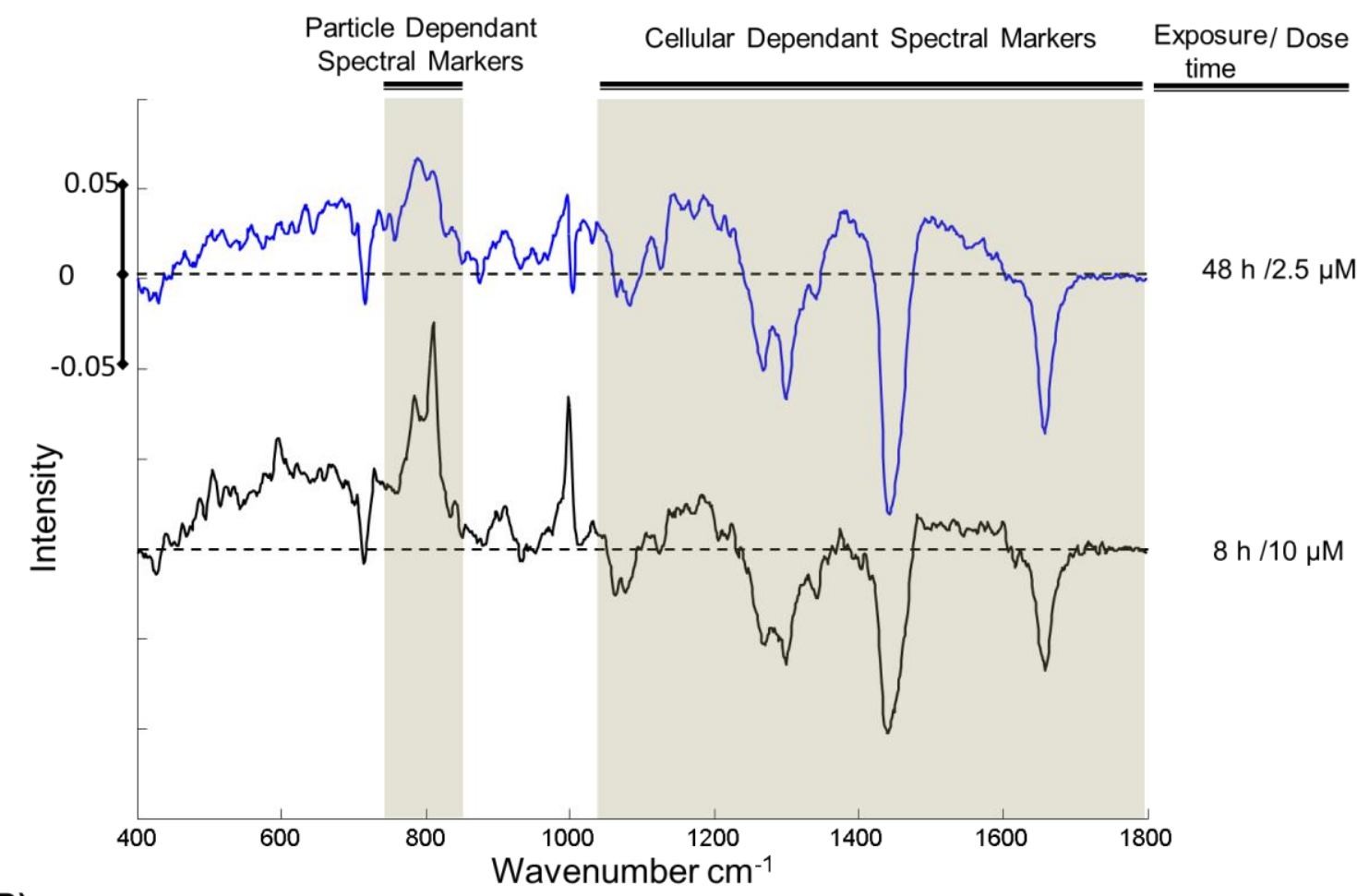

(B)

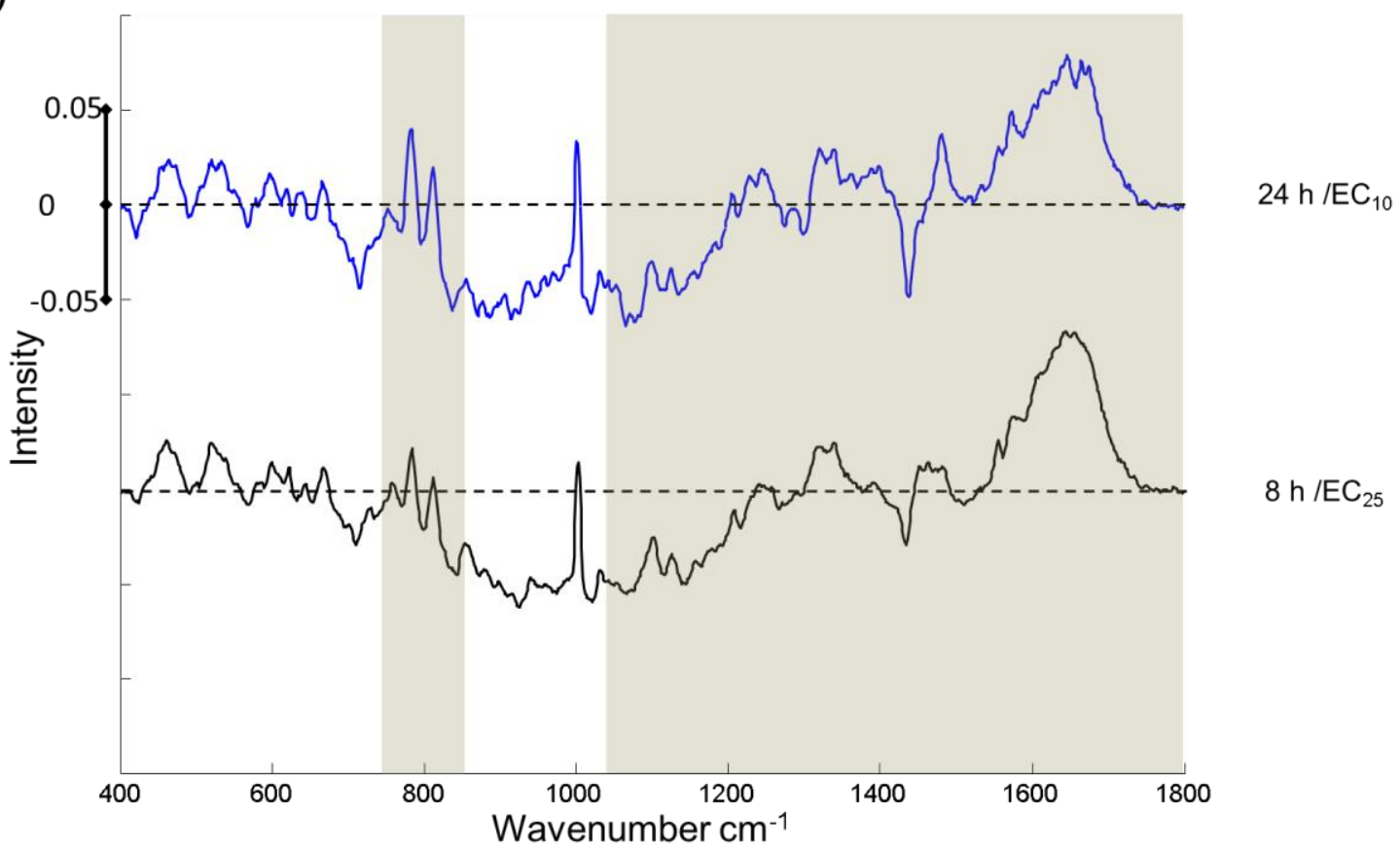

Fig.5 Comparisons of the loading 1 of PCA of cytoplasm for exposed and control cells. (A) After $8 \mathrm{~h}$ exposure to $10 \mu \mathrm{M}$ (red) and $48 \mathrm{~h} 2.5 \mu \mathrm{M}$ (blue) PS-NH2. (B) After $8 \mathrm{~h}$ exposure to $\mathrm{EC}_{25}$ (red) and $24 \mathrm{~h} \mathrm{EC}_{10} \mu \mathrm{M}$ (blue) PAMAM dendrimers. Positive and negative features of the loadings relate to exposed and control cells, relatively. The areas that show similar 
responses are indicated with highlights. Loadings are offset for clarity. The dotted line represents the zero ' 0 ' point for each loading and intensity scale of $0 \pm 005$ is used for comparison $[46,94]$.

The 3D response has also been monitored within the nuclear region (nucleus and nucleolus) for cells exposed to PAMAM dendrimers, as seen in Fig.6. The spectral markers of genotoxicity, at $750-830 \mathrm{~cm}^{-1}$, showed similar patterns when cells are exposed to $\mathrm{EC}_{10}$ for 24 $\mathrm{h}$ and $\mathrm{EC}_{25}$ for $8 \mathrm{~h}$. 
(A)

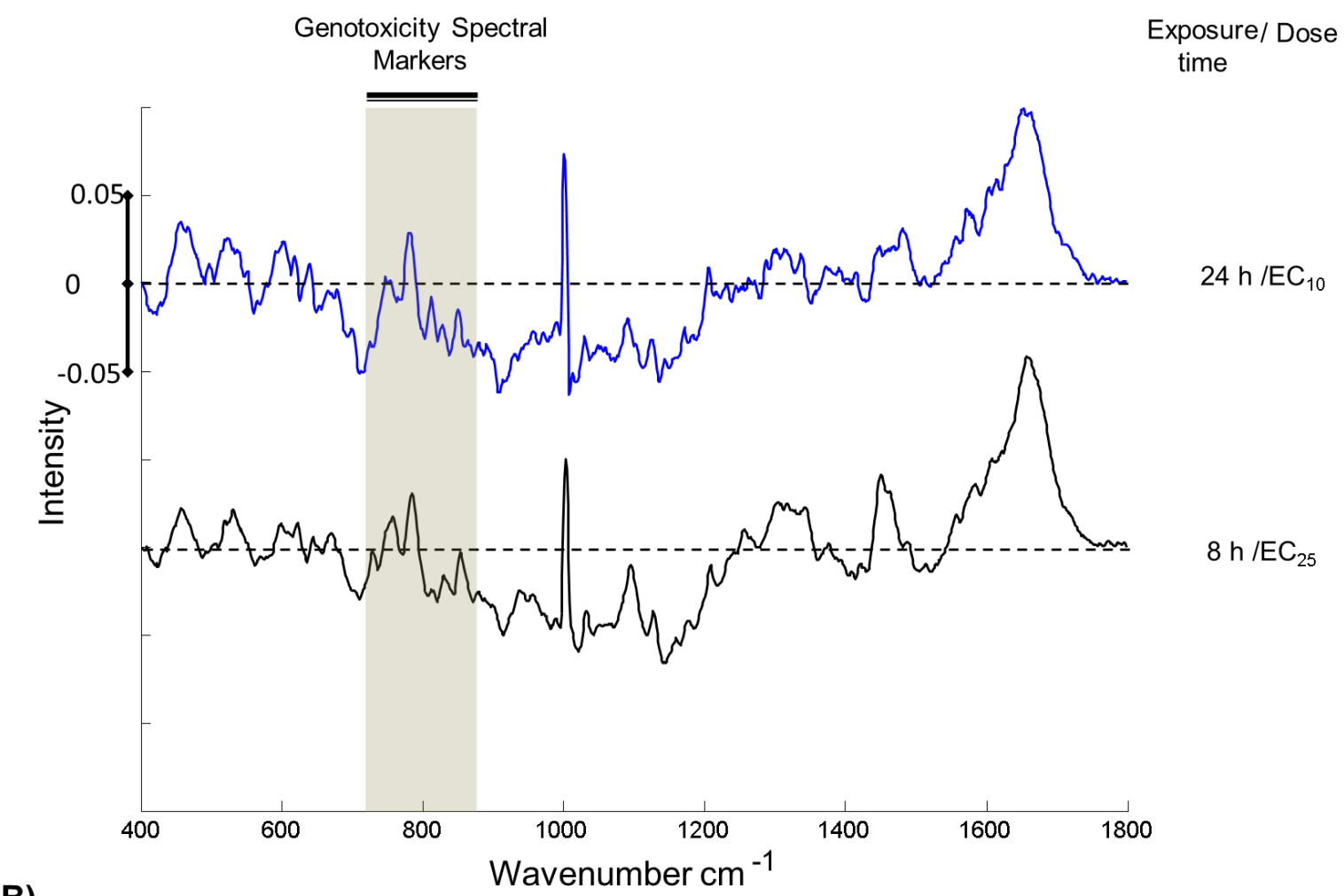

(B)

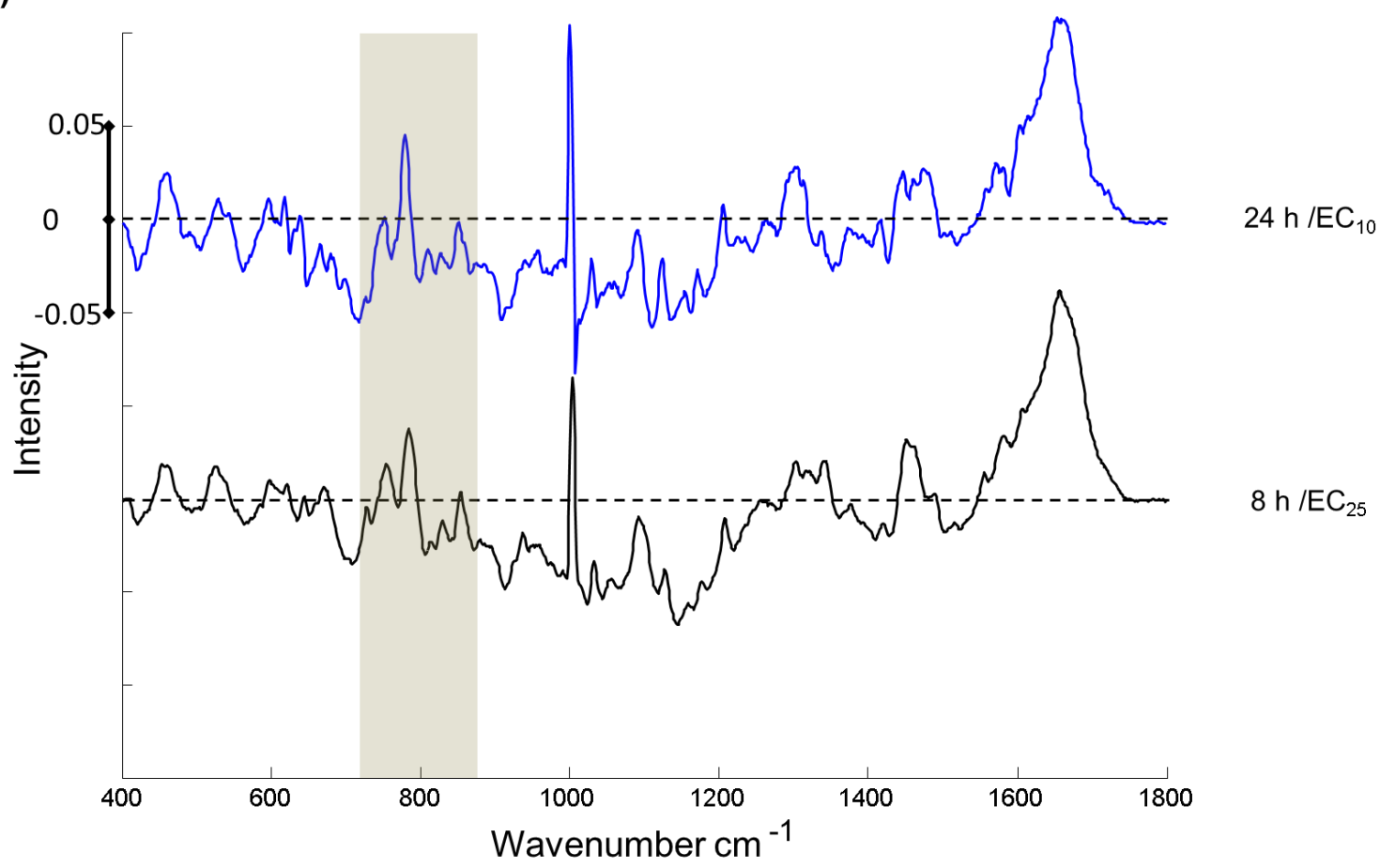

Fig.6 Comparison of the loading 1 of PCs of nucleus and nucleolus for exposed and unexposed cells after $8 \mathrm{~h}$ exposure to $\mathrm{EC}_{25}$ (red) and $24 \mathrm{~h} \mathrm{EC}_{10}$ (blue) PAMAM dendrimers.

Positive and negative features of the loadings relate to exposed and unexposed cells, 
relatively. The $750-830 \mathrm{~cm}^{-1}$ area is indicated with highlights. Loadings are offset for clarity. The dotted line represents the zero ' 0 ' point for each loading and intensity scale of $0 \pm 0.05$ is used for comparison [94].

The 3D toxic responses, which are observed based on identified spectral markers of the toxicity can be represented in 3D plots of Spectral Marker intensities which can be used for the prediction of toxic events of any nanomaterial by observation of the spectral markers. As an example, the Raman spectral data sets for PAMAM dendrimers as a function of time and dose are used as an input to build 3D plots. The four main spectral markers which have been identified throughout the study, 785, 810, 1003 and $1438 \mathrm{~cm}^{-1}$, are simultaneously plotted against time point and dose. The band intensities of the identified markers have been observed to change as a function of dose and time, which is manifest as an increase in the positive features, or inversion to negative features, of the loading of the PCA. The increase of the intensity of positive features can be attributed to an increase, accumulation and/or a conformational change of the biochemical constituent, whereas inversion to the negative features indicates damage and loss of the constituent upon exposure, in both cases compared to unexposed control. Fig.7 shows the representative 3D mesh and contour plot created to show spectral marker intensity distribution of the 785 and $810 \mathrm{~cm}^{-1}$ in the cytoplasm as a function of time and dose of PAMAM G5 exposure. A colour scale is provided to show intensity of the spectral marker for contour plots. In the 3D plots based on spectral marker intensities, a range of areas from safe to toxic can be identified and the plots can be further applied to different nanoparticles and pharmaceuticals to identify the range they fit into. The 785 and $810 \mathrm{~cm}^{-1}$ spectral marker was identified as one of the most significant markers observed throughout the study, showing dramatic and progressive changes as a function of dose and exposure times. The band at $785 \mathrm{~cm}^{-1}$ (nucleic acid) showed a progressive decrease with increasing dose, 
whereas an increase followed by decrease is observed with extended exposure times (Fig.7(A)). When the intensity of the spectral marker band at $785 \mathrm{~cm}^{-1}$ is correlated with $24 \mathrm{~h}$ cellular \%viability determined by $\mathrm{AB}$ assay as $\mathrm{EC}_{10}, \mathrm{EC}_{25}, \mathrm{EC}_{50}$ and $\mathrm{EC}_{75}$, a significant correlation is observed and the intensity of the marker is reduced with reducing viability. The approximate viability values obtained from $\mathrm{EC}_{50}$ curve fits after $24 \mathrm{~h}$ exposure are presented in Fig.7(B) in white text. The origin of the $810 \mathrm{~cm}^{-1}$ band has been identified as changes in cytoplasmic RNA as a result of formation of ROS. The intensity reaches its highest value at $\sim 24-48 \mathrm{~h}$, after which a significant loss of the signature of cytoplasmic RNA can be observed (Fig.7(C and D).

(A)

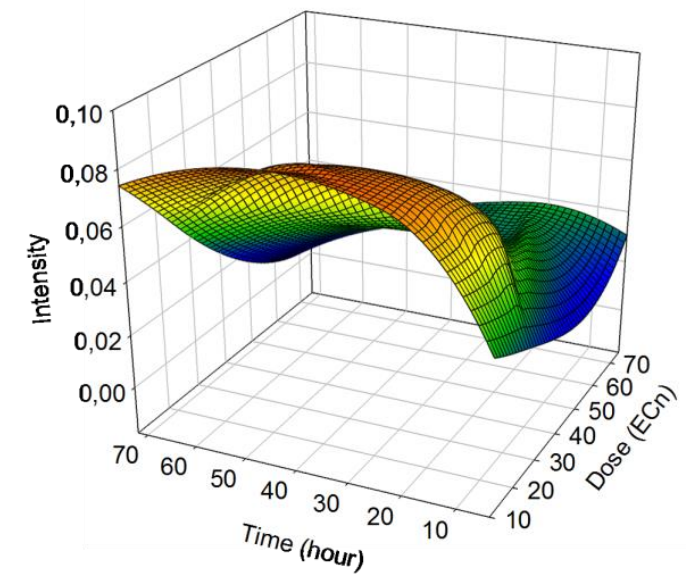

C)

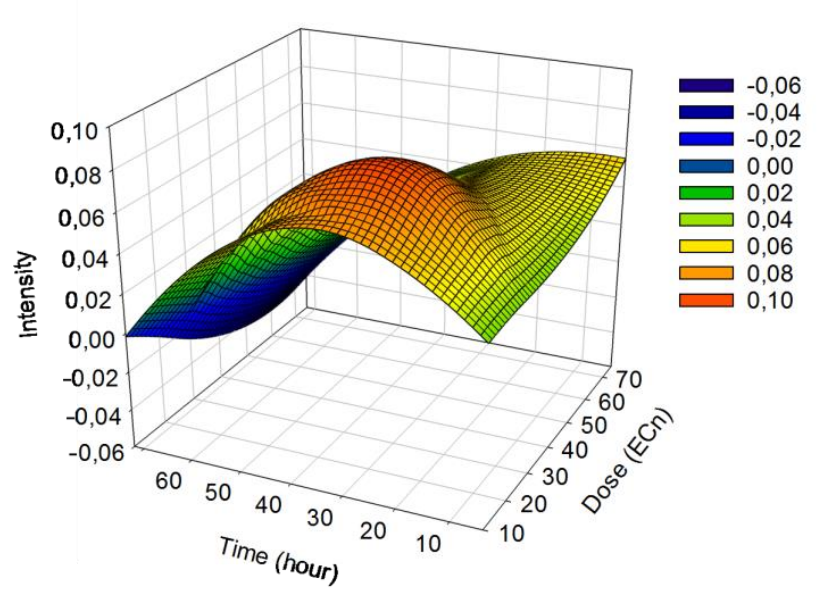

(B)

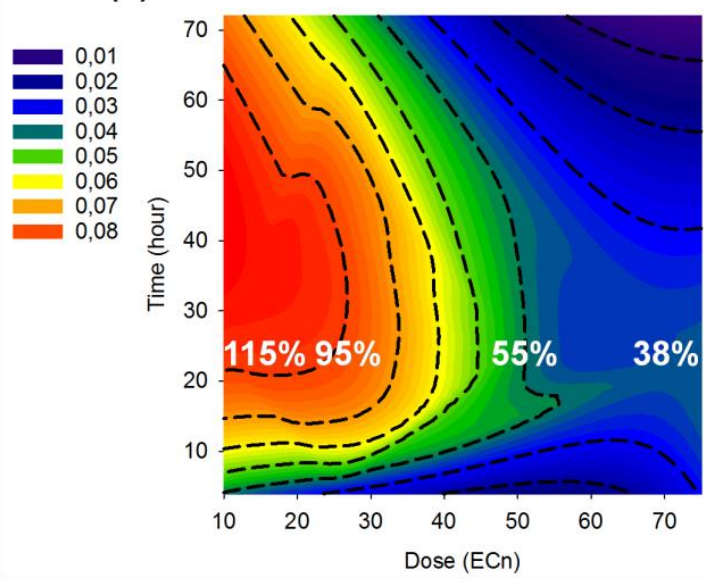

(D)

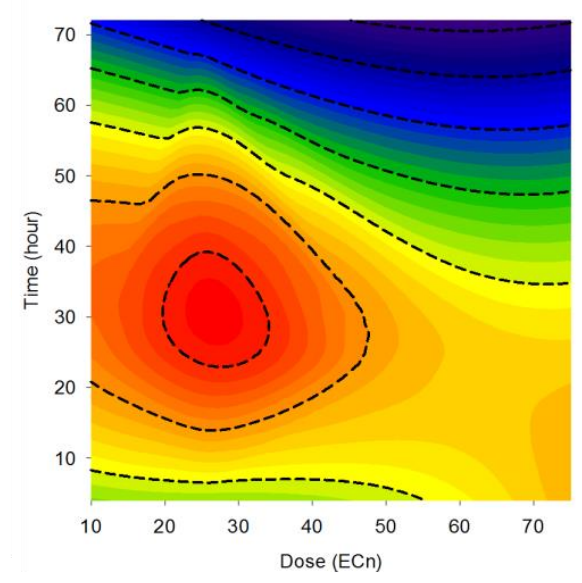


Fig.7 3D mesh and contour plot of $785(\mathrm{~A}, \mathrm{~B})$ and $810 \mathrm{~cm}^{-1}(\mathrm{C}, \mathrm{D})$ spectral marker intensity as a function of time $(\mathrm{h})$ and dose $\left(\mathrm{EC}_{\mathrm{n}}\right)$. The $24 \mathrm{~h}$ cellular viability at $\mathrm{EC}_{10}, \mathrm{EC}_{25}, \mathrm{EC}_{50}$ and $\mathrm{EC}_{75}$ determined by $\mathrm{AB}$ assay are indicated with percentages on the plot (white).

However, this relation is not observed for the band at $810 \mathrm{~cm}^{-1}$ spectral marker. The different dose/time dependencies of the spectral markers can be related to consecutive cascade of events occurring within the cell upon a toxicant exposure. The band at $786 \mathrm{~cm}^{-1}$ originates from the ring breathing modes of nucleic acid bases ( $\mathrm{U}, \mathrm{T}$ and $\mathrm{C}$ ) and also from O-P-O backbone. Therefore, the presence of the band in the features of the loadings can be attributed to nucleic acids, RNA and/or DNA [82, 103, 104]. On the other hand, the band at $810 \mathrm{~cm}^{-1}$ is known to be more specific to sugar-phosphate diester of RNA $[105,106]$. The cytoplasmic RNA significantly gets affected by oxidative stress and increased ROS levels results repression of translation and accumulation of non-coding RNAs. A concomitant increase in the $785 \mathrm{~cm}^{-1}$ band can also be observed in short exposure times. A secondary increase in $785 \mathrm{~cm}^{-1}$ band, which evolves different, compared to $810 \mathrm{~cm}^{-1}$ band can be attributed to independent toxic event in the cell.

Notably, time evolution of the ROS dependant cytoplasmic RNA band $\left(810 \mathrm{~cm}^{-1}\right)$ show significant differences to the simulation models of Maher et al. [102] (Fig.8). When the simulated cytotoxic (A) and spectroscopic data (B) are analysed, while similar patterns are observed, the evolution occurs over different timescale, which can be related to the formation of ROS as an initiating toxic event followed by changes in cytoplasmic RNA at later times, as response to ROS formation. However, due to the lack of data in our experimental model, the plots remained limited to show time related pattern in extended exposure times. 
(A)

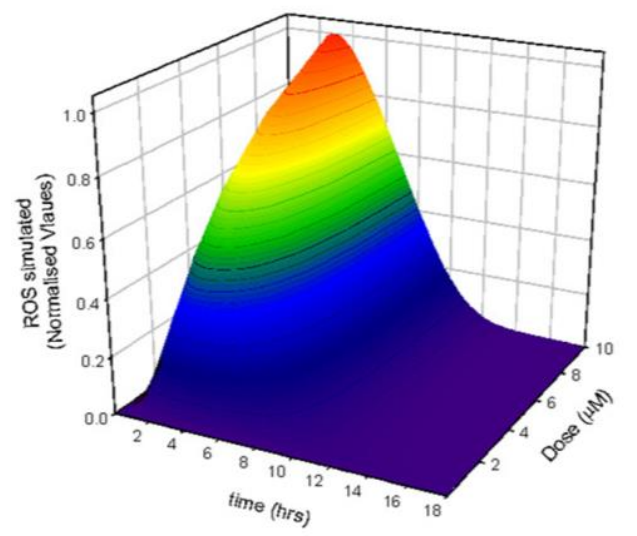

(B)

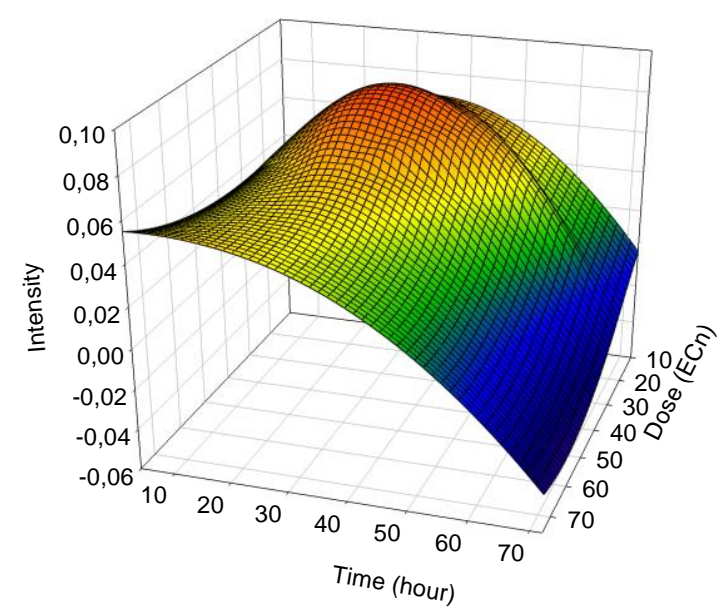

Fig.8 3D mesh plots representing the response of (A) Simulated model of Reactive oxygen species (B) $810 \mathrm{~cm}^{-1}$ spectral marker intensity. (A) is adapted from Maher et al.[102]

The $1003 \mathrm{~cm}^{-1}$ (protein) and $1438 \mathrm{~cm}^{-1}$ (lipotoxicity) spectral markers have been also plotted in the same format and are shown in Fig.9. The 3D plots show consistency with the $785 \mathrm{~cm}^{-1}$ spectral marker in terms of cellular viability. After $24 \mathrm{~h}$ exposure, with increasing dose, cellular viability is decreased with concomitant decrease in the intensity of the bands. Especially, at longer time points, the graphs remained limited due to lack of data. 
(A)

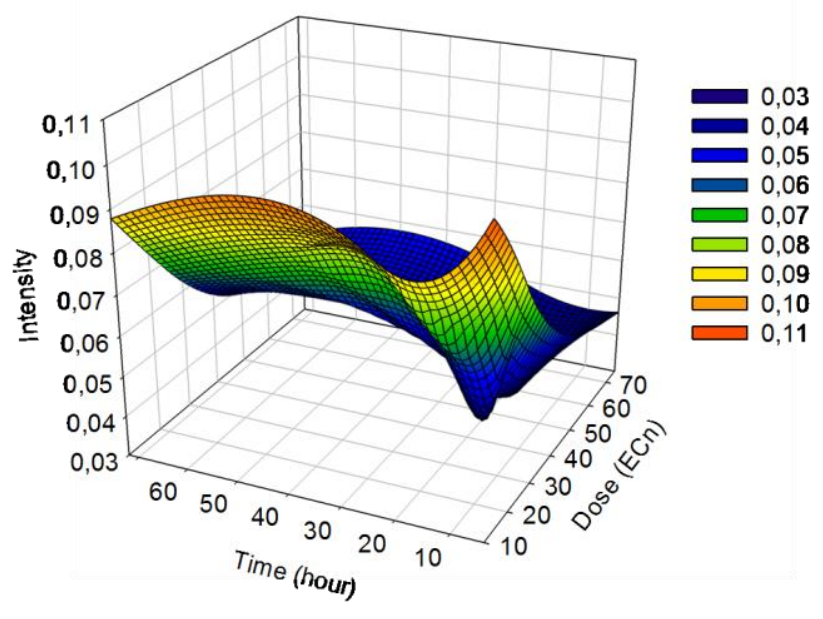

(C)

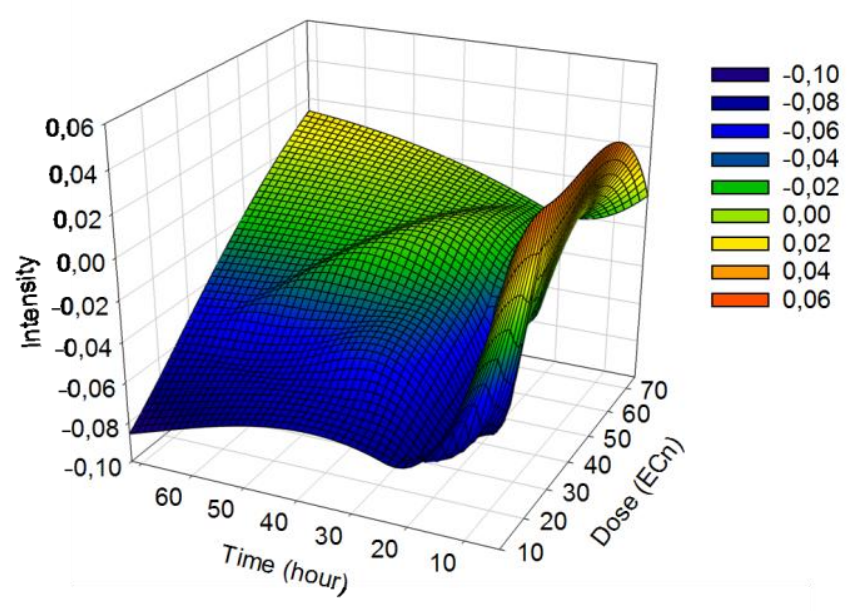

(B)

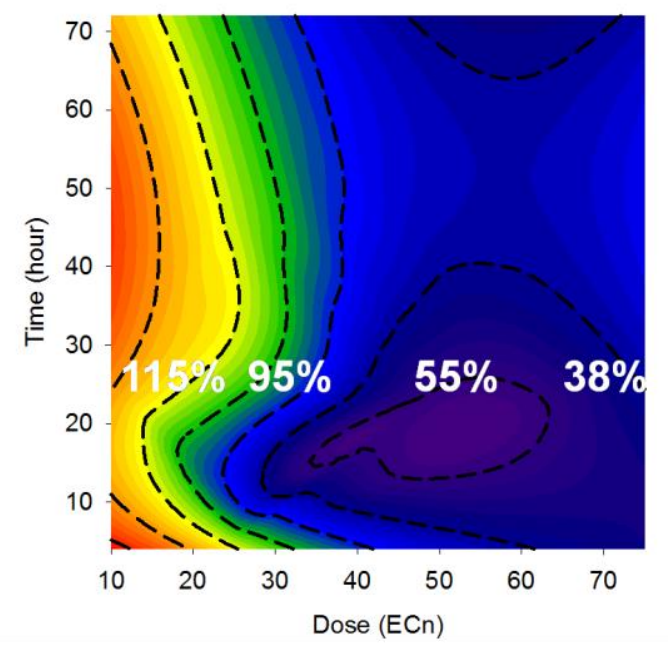

(D)

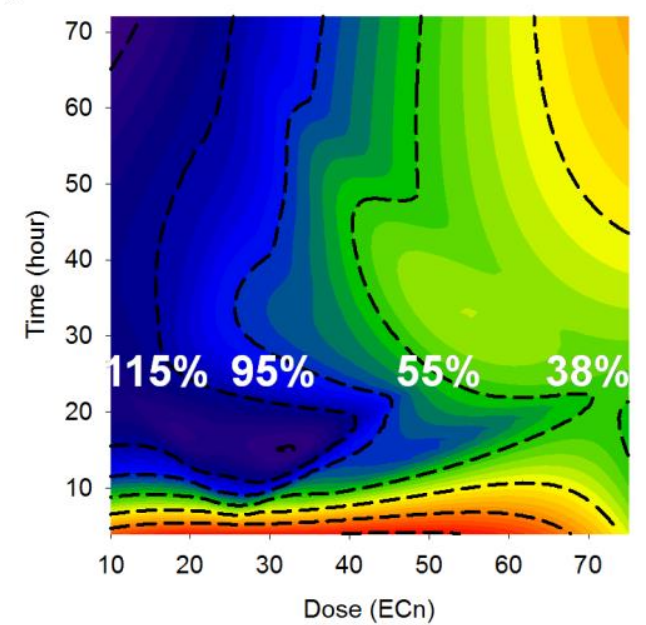

Fig.9 3D mesh and contour plot 1003 (A and B) and $1438\left(\mathrm{C}\right.$ and D) $\mathrm{cm}^{-1}$ spectral marker intensity as a function of time and dose. The cellular viability at $\mathrm{EC}_{10}, \mathrm{EC}_{25}, \mathrm{EC}_{50}$ and $\mathrm{EC}_{75}$ are indicated with percentages on the plot (white).

\section{Future perspectives}

The established 3D plots help to illustrate the potential of Raman microspectroscopy as a 'High Content Nanotoxicological Screening technique', which can be used to determine and predict Nanotoxicity based on spectral intensities. Although the plots are created for PAMAM dendrimers, the markers are derived from intrinsic properties of biochemical constituents of 
the cells which are related to individual cellular events and the plots can be applied to a wide range of nanomaterials and potentially even to the pharmaceuticals.

Further refinements on the development of the plots can be achieved by the use of multiple time points and doses. With improved sensitivities of Raman microspectrometers, or through CARS and SRS techniques, real-time live cell monitoring can potentially be achieved. Moreover, the use of more sophisticated and quantitative multivariate techniques, such as Partial Least Squares Regression (PLSR) and Multivariate Curve Resolution Alternating Least Squares (MCR-ALS), for analysis of Raman spectral data sets for the identification of spectral marker intensities can enable the establishment of improved 3D plots.

Nanocarrier systems for drug delivery applications has attracted a significant attention to achieve targeted delivery of drugs in area of interest and to develop personalized medicine [107-111]. The identified spectral markers and spectral features of Raman active nanocarriers can further be utilized to track the localization of the nanocarriers within a cell, as well as to monitir responses produced in cells upon release of drug from carriers. Notably, the nanocarriers are localised within the cell, initially in endosomes, and can be subsequently trafficked to lysosomes and, for example the endoplasmic reticulum, and the local environment of the nanoparticles and therefore the encapsulating vesicle can also be characterised by Raman microspectroscopic mapping [74]. In the case where random points in the cytoplasm or nucleus are recorded, at least at low to moderate doses, little or no contribution of the nanoparticles or their encapsulating environment is observed, and the recorded responses are primarily due to the cellular responses.

\section{Conclusion}

The work presented in this study has demonstrated the potential of Raman microspectroscopy as a label free high content toxicological screening technique which can utilized for the rapid advances in nanotoxicology and nanomedicine and investigation of wide range of nanomaterials real-time in a rapid, label-free way. The use of Raman microspectroscopy as a toxicological assessment protocol can provide many advantages over current techniques by 
using intrinsic features of biomaterials. The technique provides a multifaceted data which gives information about localisation and trafficking, cellular viability, mechanism of interaction, response rates and cell death mechanism as well as pathways leading to cell death. Continued development of instrumental technologies, and the emergence of nonlinear Raman techniques, promise real time, live cell monitoring of nanoparticle uptake and cellular response, for which more sophisticated, multivariate analysis and data-mining techniques will be required.

\section{Acknowledgements}

This work was supported by Science Foundation Ireland Principle Investigator Award 11/PI/1108.

\section{Conflict of Interest}

The authors declare that there are no conflicts of interest.

\section{References}

1. Oberdörster G, Maynard A, Donaldson K, Castranova V, Fitzpatrick J, Ausman K et al. Principles for characterizing the potential human health effects from exposure to nanomaterials: elements of a screening strategy. Particle and fibre toxicology. 2005;2(1):8.

2. Donaldson K, Stone V, Tran CL, Kreyling W, Borm PJ. Nanotoxicology. Occup Environ Med. 2004; 61(9): 727-8.

3. Institute of Medicine (US) Roundtable on Environmental Health Sciences, Research, and Medicine. Implications of Nanotechnology for Environmental Health Research. Washington (DC): National Academies Press (US); 2005. doi: 10.17226/11248.

4. Guisbiers G. Size-Dependent Materials Properties Toward a Universal Equation. Nanoscale Research Letters. 2010;5(7):1132-6. 
5. Jagiello K, Chomicz B, Avramopoulos A, Gajewicz A, Mikolajczyk A, Bonifassi P et al. Size-dependent electronic properties of nanomaterials: How this novel class of nanodescriptors supposed to be calculated? Structural Chemistry. 2017;28(3):635-43.

6. Sperling RA, Parak WJ. Surface modification, functionalization and bioconjugation of colloidal inorganic nanoparticles. Phil Trans R Soc. 2010;368(1915):1333-83.

7. Recent Trends in Nanotechnology and Materials Science. 1 ed. Springer International Publishing; 2014. doi:10.1007/978-3-319-04516-0.

8. Laurvick CAC, Singaraju B. Nanotechnology in aerospace systems. IEEE Aerospace and Electronic Systems Magazine. 2003;18(9):18-22.

9. Raj S, Jose S, Sumod US, Sabitha M. Nanotechnology in cosmetics: Opportunities and challenges. Journal of Pharmacy \& Bioallied Sciences. 2012;4(3):186-93.

10. Kawasaki ES, Player A. Nanotechnology, nanomedicine, and the development of new, effective therapies for cancer. Nanomedicine : nanotechnology, biology, and medicine. 2005;1(2):101-9.

11. Park K. Nanotechnology: What it can do for drug delivery. Journal of controlled release : official journal of the Controlled Release Society. 2007;120(1-2):1-3.

12. Sailor MJ, Link JR. "Smart dust": nanostructured devices in a grain of sand. Chemical Communications. 2005(11):1375-83.

13. Godbey WT, Wu KK, Mikos AG. Tracking the intracellular path of poly(ethylenimine)/DNA complexes for gene delivery. Proceedings of the National Academy of Sciences of the United States of America. 1999;96(9):5177-81.

14. Tosi G, Bortot B, Ruozi B, Dolcetta D, Vandelli MA, Forni F et al. Potential use of polymeric nanoparticles for drug delivery across the blood-brain barrier. Current medicinal chemistry. 2013;20(17):2212-25. 
15. Nune SK, Gunda P, Thallapally PK, Lin Y-Y, Forrest ML, Berkland CJ. Nanoparticles for biomedical imaging. Expert opinion on drug delivery. 2009;6(11):1175-94.

16. Brigger I, Dubernet C, Couvreur P. Nanoparticles in cancer therapy and diagnosis. Advanced Drug Delivery Reviews. 2012;64, Supplement:24-36.

17. Nel AE, Madler L, Velegol D, Xia T, Hoek EMV, Somasundaran P et al. Understanding biophysicochemical interactions at the nano-bio interface. Nat Mater. 2009;8(7):543-57.

18. Society R, Engineering RA. Nanoscience and Nanotechnologies: Opportunities and Uncertainties. Royal Society; 2004. http://www.nanotec.org.uk/finalReport.htm. Accessed August 2017.

19. OECD. Safety of manufactured nanomaterials. http://www.oecd.org/science/nanosafety/. Accessed August 2017.

20. OECD. OECD, Series on the Safety of Manufactured Nanomaterials. 2010. pp. 46.

21. EU 'NanoSafetyCluster'. NanoSafety Cluster. https://www.nanosafetycluster.eu/. Accessed August 2017.

22. Mosmann T. Rapid colorimetric assay for cellular growth and survival: application to proliferation and cytotoxicity assays. Journal of immunological methods. 1983;65(1-2):55-63. 23. Berridge MV, Herst PM, Tan AS. Tetrazolium dyes as tools in cell biology: new insights into their cellular reduction. Biotechnology annual review. 2005;11:127-52.

24. Rampersad SN. Multiple Applications of Alamar Blue as an Indicator of Metabolic Function and Cellular Health in Cell Viability Bioassays. Sensors. 2012;12(9): 12347-60.

25. Vega-Avila E, Pugsley MK. An overview of colorimetric assay methods used to assess survival or proliferation of mammalian cells. Proceedings of the Western Pharmacology Society. 2011;54:10-4.

26. Brzoska M, Langer K, Coester C, Loitsch S, Wagner TO, Mallinckrodt C. Incorporation of biodegradable nanoparticles into human airway epithelium cells-in vitro study of the suitability 
as a vehicle for drug or gene delivery in pulmonary diseases. Biochem Biophys Res Commun. 2004;318(2):562-70.

27. Karlsson HL, Cronholm P, Gustafsson J, Moller L. Copper oxide nanoparticles are highly toxic: a comparison between metal oxide nanoparticles and carbon nanotubes. Chemical research in toxicology. 2008;21(9):1726-32.

28. Herzog E, Casey A, Lyng FM, Chambers G, Byrne HJ, Davoren M. A new approach to the toxicity testing of carbon-based nanomaterials--the clonogenic assay. Toxicology letters. 2007;174(1-3):49-60.

29. Casey A, Herzog E, Lyng FM, Byrne HJ, Chambers G, Davoren M. Single walled carbon nanotubes induce indirect cytotoxicity by medium depletion in A549 lung cells. Toxicology Letters. 2008;179(2):78-84.

30. Sandin P, Fitzpatrick LW, Simpson JC, Dawson KA. High-speed imaging of Rab family small GTPases reveals rare events in nanoparticle trafficking in living cells. ACS nano. 2012;6(2):1513-21.

31. Fazlollahi F, Angelow S, Yacobi NR, Marchelletta R, Yu ASL, Hamm-Alvarez SF et al. Polystyrene nanoparticle trafficking across MDCK-II. Nanomedicine : nanotechnology, biology, and medicine. 2011;7(5):588-94.

32. Jan E, Byrne SJ, Cuddihy M, Davies AM, Volkov Y, Gun'ko YK et al. High-content screening as a universal tool for fingerprinting of cytotoxicity of nanoparticles. ACS nano. 2008;2(5):928-38.

33. Handbook Of Biological Confocal Microscopy. Springer US; 2006. doi: 10.1007/978-0$387-45524-2$

34. Radio NM, Breier JM, Shafer TJ, Mundy WR. Assessment of chemical effects on neurite outgrowth in PC12 cells using high content screening. Toxicological sciences : an official journal of the Society of Toxicology. 2008;105(1):106-18. 
35. Ruan B, Pong K, Jow F, Bowlby M, Crozier RA, Liu D et al. Binding of rapamycin analogs to calcium channels and FKBP52 contributes to their neuroprotective activities. Proc Natl Acad Sci U S A. 2008;105(1):33-8.

36. Ding GJ, Fischer PA, Boltz RC, Schmidt JA, Colaianne JJ, Gough A et al. Characterization and quantitation of NF-kappaB nuclear translocation induced by interleukin-1 and tumor necrosis factor-alpha. Development and use of a high capacity fluorescence cytometric system. The Journal of biological chemistry. 1998;273(44):28897-905.

37. Zock JM. Applications of High Content Screening in Life Science Research. Combinatorial Chemistry \& High Throughput Screening. 2009;12(9):870-6.

38. Sarker KP, Kataoka H, Chan A, Netherton SJ, Pot I, Huynh MA et al. ING2 as a novel mediator of transforming growth factor-beta-dependent responses in epithelial cells. The Journal of biological chemistry. 2008;283(19):13269-79.

39. Liebel U, Link W. Meeting report: trends and challenges in high content analysis. Biotechnology journal. 2007;2(8):938-40.

40. Brayden DJ, Cryan S-A, Dawson KA, O’Brien PJ, Simpson JC. High-content analysis for drug delivery and nanoparticle applications. Drug Discovery Today. 2015;20(8):942-57.

41. Wang EC, Wang AZ. Nanoparticles And Their Applications In Cell And Molecular Biology. Integrative biology : quantitative biosciences from nano to macro. 2014;6(1):9-26.

42. Manke A, Wang L, Rojanasakul Y. Mechanisms of Nanoparticle-Induced Oxidative Stress and Toxicity. BioMed Research International. 2013;2013:15.

43. Sierra MI, Valdés A, Fernández AF, Torrecillas R, Fraga MF. The effect of exposure to nanoparticles and nanomaterials on the mammalian epigenome. International journal of nanomedicine. 2016;11:6297-306. 
44. Mukherjee SP, Byrne HJ. Polyamidoamine dendrimer nanoparticle cytotoxicity, oxidative stress, caspase activation and inflammatory response: experimental observation and numerical simulation. Nanomedicine : nanotechnology, biology, and medicine. 2013;9(2):202-11.

45. Mukherjee SP, Davoren M, Byrne HJ. In vitro mammalian cytotoxicological study of PAMAM dendrimers - towards quantitative structure activity relationships. Toxicology in vitro : an international journal published in association with BIBRA. 2010;24(1):169-77.

46. Efeoglu E, Casey A, Byrne HJ. In vitro monitoring of time and dose dependent cytotoxicity of aminated nanoparticles using Raman spectroscopy. Analyst. 2016;141(18):5417-31.

47. Naha PC, Davoren M, Lyng FM, Byrne HJ. Reactive oxygen species (ROS) induced cytokine production and cytotoxicity of PAMAM dendrimers in J774A.1 cells. Toxicology and Applied Pharmacology. 2010;246(1-2):91-9.

48. Naha PC, Byrne HJ. Generation of intracellular reactive oxygen species and genotoxicity effect to exposure of nanosized polyamidoamine (PAMAM) dendrimers in PLHC-1 cells in vitro. Aquatic toxicology. 2013;132-133:61-72.

49. Martinez E, Lagunas A, Mills CA, Rodriguez-Segui S, Estevez M, Oberhansl S et al. Stem cell differentiation by functionalized micro- and nanostructured surfaces. Nanomedicine. 2009;4(1):65-82.

50. Efeoglu E, Maher MA, Casey A, Byrne HJ. Label-free, high content screening using Raman microspectroscopy: the toxicological response of different cell lines to amine-modified polystyrene nanoparticles (PS-NH 2$)$. Analyst. 2017;142(18):3500-13.

51. Mori T, Takada H, Ito S, Matsubayashi K, Miwa N, Sawaguchi T. Preclinical studies on safety of fullerene upon acute oral administration and evaluation for no mutagenesis. Toxicology. 2006;225(1):48-54. 
52. Kim HR, Park YJ, Shin DY, Oh SM, Chung KH. Appropriate In Vitro Methods for Genotoxicity Testing of Silver Nanoparticles. Environmental Health and Toxicology. 2013;28:e2013003.

53. Jin Y, Kannan S, Wu M, Zhao JX. Toxicity of luminescent silica nanoparticles to living cells. Chemical research in toxicology. 2007;20(8):1126-33.

54. Hillegass JM, Shukla A, Lathrop SA, MacPherson MB, Fukagawa NK, Mossman BT. Assessing nanotoxicity in cells in vitro. Wiley interdisciplinary reviews Nanomedicine and nanobiotechnology. 2010;2(3):219-31.

55. Chew WS, Poh KW, Siddiqi NJ, Alhomida AS, Yu LE, Ong WY. Short- and long-term changes in blood miRNA levels after nanogold injection in rats-potential biomarkers of nanoparticle exposure. Biomarkers: biochemical indicators of exposure, response, and susceptibility to chemicals. 2012;17(8):750-7.

56. Holder AL, Goth-Goldstein R, Lucas D, Koshland CP. Particle-induced artifacts in the MTT and LDH viability assays. Chemical research in toxicology. 2012;25(9):1885-92.

57. Casey A, Herzog E, Davoren M, Lyng FM, Byrne HJ, Chambers G. Spectroscopic analysis confirms the interactions between single walled carbon nanotubes and various dyes commonly used to assess cytotoxicity. Carbon. 2007;45(7):1425-32.

58. Riss TL, Moravec RA, Niles AL, Duellman S, Benink HA, Worzella TJ et al. Cell Viability Assays. In: Sittampalam GS, Coussens NP, Brimacombe K, Grossman A, Arkin M, Auld D et al., editors. Assay Guidance Manual. Bethesda (MD): Eli Lilly \& Company and the National Center for Advancing Translational Sciences; 2004.

59. Shapero K, Fenaroli F, Lynch I, Cottell DC, Salvati A, Dawson KA. Time and space resolved uptake study of silica nanoparticles by human cells. Molecular bioSystems. $2011 ; 7(2): 371-8$. 
60. Salvati A, Aberg C, dos Santos T, Varela J, Pinto P, Lynch I et al. Experimental and theoretical comparison of intracellular import of polymeric nanoparticles and small molecules: toward models of uptake kinetics. Nanomedicine : nanotechnology, biology, and medicine. 2011;7(6):818-26.

61. Suh H, Jeong B, Liu F, Kim SW. Cellular Uptake Study of Biodegradable Nanoparticles in Vascular Smooth Muscle Cells. Pharmaceutical Research. 1998;15(9):1495-8.

62. ACS. American Chemical Society International Historic Chemical Landmarks. The Raman Effect. http://www.acs.org/content/acs/en/education/whatischemistry/landmarks/ramaneffect. html. Accessed July 2017.

63. Adjouri C, Elliasmine A, Le Duff Y. Low-light-level Raman spectroscopy using a chargecoupled device detector. (Eugene, Oregon): Spectroscopy 1996. pp. 46-9.

64. Butler HJ, Ashton L, Bird B, Cinque G, Curtis K, Dorney J et al. Using Raman spectroscopy to characterize biological materials. Nat Protocols. 2016;11(4):664-87.

65. Stiles PL, Dieringer JA, Shah NC, Van Duyne RP. Surface-enhanced Raman spectroscopy. Annual review of analytical chemistry (Palo Alto, Calif). 2008;1:601-26.

66. Zhang Z, Sheng S, Wang R, Sun M. Tip-Enhanced Raman Spectroscopy. Analytical chemistry. 2016;88(19):9328-46.

67. Zheltikov AM. Coherent anti-Stokes Raman scattering: from proof-of-the-principle experiments to femtosecond CARS and higher order wave-mixing generalizations. Journal of Raman Spectroscopy. 2000;31(8-9):653-67.

68. Pezacki JP, Blake JA, Danielson DC, Kennedy DC, Lyn RK, Singaravelu R. Chemical contrast for imaging living systems: molecular vibrations drive CARS microscopy. Nature chemical biology. 2011;7(3):137-45.

69. Walton AG, Deveney MJ, Koenig JL. Raman spectroscopy of calcified tissue. Calcified Tissue Research. 1970;6(1):162-7. 
70. Breve GJPaJ. Whole Cell Studies and Tissue Characterization by Raman Spectroscopy. “Biomedical Applications of Spectroscopy”. New York: John Wiley and Sons; 1996.

71. Bonnier F, Petitjean F, Baker MJ, Byrne HJ. Improved protocols for vibrational spectroscopic analysis of body fluids. Journal of biophotonics. 2014;7(3-4):167-79.

72. Bonnier F, Mehmood A, Knief P, Meade AD, Hornebeck W, Lambkin $\mathrm{H}$ et al. In vitro analysis of immersed human tissues by Raman microspectroscopy. Journal of Raman Spectroscopy. 2011;42(5):888-96.

73. Dorney J, Bonnier F, Garcia A, Casey A, Chambers G, Byrne HJ. Identifying and localizing intracellular nanoparticles using Raman spectroscopy. Analyst. 2012;137(5):1111-9.

74. Efeoglu E, Keating M, McIntyre J, Casey A, Byrne HJ. Determination of nanoparticle localisation within subcellular organelles in vitro using Raman spectroscopy. Analytical Methods. 2015;7(23):10000-17.

75. Jermyn M, Mok K, Mercier J, Desroches J, Pichette J, Saint-Arnaud K et al. Intraoperative brain cancer detection with Raman spectroscopy in humans. Science Translational Medicine. 2015;7(274):274ra19.

76. Keating ME, Bonnier F, Byrne HJ. Spectral cross-correlation as a supervised approach for the analysis of complex Raman datasets: the case of nanoparticles in biological cells. Analyst. 2012;137(24):5792-802.

77. Carey PR. Biochemical applications of Raman and resonance Raman spectroscopies. Accessed from http://nla.gov.au/nla.cat-vn1781434. New York: Academic Press; 1982.

78. Klein K, Gigler Alexander M, Aschenbrenner T, Monetti R, Bunk W, Jamitzky F et al. Label-Free Live-Cell Imaging with Confocal Raman Microscopy. Biophysical journal. 2012;102(2):360-8 
79. Krauss SD, Petersen D, Niedieker D, Fricke I, Freier E, El-Mashtoly SF et al. Colocalization of fluorescence and Raman microscopic images for the identification of subcellular compartments: a validation study. Analyst. 2015;140(7):2360-8.

80. Carvalho LF, Bonnier F, O'Callaghan K, O'Sullivan J, Flint S, Byrne HJ et al. Raman microspectroscopy for rapid screening of oral squamous cell carcinoma. Experimental and molecular pathology. 2015;98(3):502-9.

81. Bonnier F, Knief P, Lim B, Meade AD, Dorney J, Bhattacharya K et al. Imaging live cells grown on a three dimensional collagen matrix using Raman microspectroscopy. Analyst. 2010;135(12):3169-77.

82. Notingher I, Verrier S, Haque S, Polak JM, Hench LL. Spectroscopic study of human lung epithelial cells (A549) in culture: living cells versus dead cells. Biopolymers. 2003;72(4):23040.

83. Swain RJ, Kemp SJ, Goldstraw P, Tetley TD, Stevens MM. Assessment of Cell Line Models of Primary Human Cells by Raman Spectral Phenotyping. Biophysical journal. 2010;98(8):1703-11.

84. Li J, Strong R, Trevisan J, Fogarty SW, Fullwood NJ, Jones KC et al. Dose-related alterations of carbon nanoparticles in mammalian cells detected using biospectroscopy: potential for real-world effects. Environmental science \& technology. 2013;47(17):10005-11. 85. Li J, Ying GG, Jones KC, Martin FL. Real-world carbon nanoparticle exposures induce brain and gonadal alterations in zebrafish (Danio rerio) as determined by biospectroscopy techniques. Analyst. 2015;140(8):2687-95.

86. Rhiem S, Riding MJ, Baumgartner W, Martin FL, Semple KT, Jones KC et al. Interactions of multiwalled carbon nanotubes with algal cells: quantification of association, visualization of uptake, and measurement of alterations in the composition of cells. Environ Pollut. 2015;196:431-9. 
87. Draux F, Jeannesson P, Beljebbar A, Tfayli A, Fourre N, Manfait M et al. Raman spectral imaging of single living cancer cells: a preliminary study. Analyst. 2009;134(3):542-8.

88. Miljkovic M, Chernenko T, Romeo MJ, Bird B, Matthaus C, Diem M. Label-free imaging of human cells: algorithms for image reconstruction of Raman hyperspectral datasets. Analyst. 2010;135(8):2002-13.

89. Byrne HJ, Sockalingum GD, Stone N. Chapter 4 Raman Microscopy: Complement or Competitor? Biomedical Applications of Synchrotron Infrared Microspectroscopy: A Practical Approach. The Royal Society of Chemistry; 2011. pp. 105-43.

90. Knief P, Clarke C, Herzog E, Davoren M, Lyng FM, Meade AD et al. Raman spectroscopy - a potential platform for the rapid measurement of carbon nanotube-induced cytotoxicity. Analyst. 2009;134(6):1182-91.

91. Estrela-Lopis I, Romero G, Rojas E, Moya SE and Donath E. Nanoparticle uptake and their co-localization with cell compartments - a confocal Raman microscopy study at single cell level. Journal of Physics: Conference Series. 2011;304(1):012017.

92. Bankapur A, Krishnamurthy RS, Zachariah E, Santhosh C, Chougule B, Praveen B et al. Micro-Raman Spectroscopy of Silver Nanoparticle Induced Stress on Optically-Trapped Stem Cells. PLOS ONE. 2012;7(4):e35075.

93. Ahlinder L, Ekstrand-Hammarström B, Geladi P, Österlund L. Large Uptake of Titania and Iron Oxide Nanoparticles in the Nucleus of Lung Epithelial Cells as Measured by Raman Imaging and Multivariate Classification. Biophysical journal. 2013;105(2):310-9.

94. Efeoglu E, Casey A, Byrne HJ. Determination of spectral markers of cytotoxicity and genotoxicity using in vitro Raman microspectroscopy: cellular responses to polyamidoamine dendrimer exposure. Analyst. 2017;142(20):3848-56. 
95. Efeoglu E, Maher MA, Casey A, Byrne HJ. Identification of Cell Death Mechanisms based on Raman Spectral Markers of Cyto-/Geno-Toxicity: Comparative Study of Polyamidoamine Dendrimers and Aminated Polystyrene Nanoparticles. Analyst. 2017;Submitted.

96. Treuel L, Jiang X, Nienhaus GU. New views on cellular uptake and trafficking of manufactured nanoparticles. Journal of the Royal Society, Interface / the Royal Society. 2013;10(82):20120939.

97. Doherty GJ, McMahon HT. Mechanisms of endocytosis. Annual review of biochemistry. 2009;78:857-902.

98. Mukherjee SP, Lyng FM, Garcia A, Davoren M, Byrne HJ. Mechanistic studies of in vitro cytotoxicity of poly(amidoamine) dendrimers in mammalian cells. Toxicol Appl Pharmacol. 2010;248(3):259-68.

99. Maher MA, Byrne HJ. Modification of the in vitro uptake mechanism and antioxidant levels in $\mathrm{HaCaT}$ cells and resultant changes to toxicity and oxidative stress of G4 and G6 poly(amidoamine) dendrimer nanoparticles. Analytical and bioanalytical chemistry. 2016;408(19):5295-307.

100. Dendritech I. PAMAM Dendrimers. 2017. http://www.dendritech.com/pamam.html. Accessed August 2017.

101. OECD. Adverse Outcome Pathways, Molecular Screening and Toxicogenomics. http://www.oecd.org/chemicalsafety/testing/adverse-outcome-pathways-molecular-screeningand-toxicogenomics.htm. Accessed August 2017.

102. Maher MA, Naha PC, Mukherjee SP, Byrne HJ. Numerical simulations of in vitro nanoparticle toxicity - The case of poly(amido amine) dendrimers. Toxicology in vitro. 2014;28(8):1449-60.

103. Notingher I, Hench LL. Raman microspectroscopy: a noninvasive tool for studies of individual living cells in vitro. Expert review of medical devices. 2006;3(2):215-34. 
104. Movasaghi Z, Rehman S, Rehman IU. Raman Spectroscopy of Biological Tissues. Applied Spectroscopy Reviews. 2007;42(5):493-541.

105. Small EW, Peticolas WL. Conformational dependence of the Raman scattering intensities from polynucleotides. Biopolymers. 1971;10(1):69-88.

106. Thomas GJ, Medeiros GC, Hartman KA. The dependence of raman scattering on the conformation of ribosomal RNA. Biochemical and Biophysical Research Communications. 1971;44(3):587-92.

107. Kurzątkowska K, Santiago T, Hepel M. Plasmonic nanocarrier grid-enhanced Raman sensor for studies of anticancer drug delivery. Biosens Bioelectron.2017;91:780-787.

108. Santiago T, DeVaux RS, Kurzatkowska K, Espinal R, Herschkowitz JI, Hepel M. Surfaceenhanced Raman scattering investigation of targeted delivery and controlled release of gemcitabine. Int J Nanomedicine. 2017; 12:7763-7776.

109. Stobiecka M, Dworakowska B, Jakiela S, Lukasiak A, Chalupa A, Zembrzycki K. Sensing of survivin mRNA in malignant astrocytes using graphene oxide nanocarrier-supported oligonucleotide molecular beacons. Sensors and Actuators B: Chemical. 2016; 235, 136-145.

110. Smith M and Hepel M. Controlled release of targeted anti-leukemia drugs azacitidine and decitabine monitored using surface-enhanced Raman scattering (SERS) spectroscopy. Mediterranean Journal of Chemistry. 2017; 6(4), 125-132.

111. Chon H, Lee S, Son SW, Oh CH and Choo J. Highly Sensitive Immunoassay of Lung Cancer Marker Carcinoembryonic Antigen Using Surface-Enhanced Raman Scattering of Hollow Gold Nanospheres. Anal. Chem. 2009; 81 (8), 3029-3034. 